\title{
Aging effects on neural processing of rhythm and meter
}

\section{Sarah A. Sauvé ${ }^{*}$, Emily L.W. Bolt ${ }^{1}$, Sylvie Nozaradan², Benjamin Rich Zendel ${ }^{1,3}$}

$2{ }^{1}$ Faculty of Medicine, Memorial University of Newfoundland, 300 Prince Philip Dr, St. John's, NL,

3 A1B 3V6, Canada

$4{ }^{2}$ Institute of Neuroscience, Université Catholique de Louvain, Avenue Hippocrate 10, 1200 Brussels, 5 Belgium

$6 \quad{ }^{3}$ Aging Research Centre, Newfoundland and Labrador, Grenfell Campus, Memorial University, 20

7 University Dr, Corner Brook, NL A2H 5G5, Canada

8 * Correspondence:

9 Sarah A Sauvé

10 sarah.sauve@mun.ca

11 Keywords: aging, frequency tagging, EEG, rhythm perception, beat and meter perception

12 Word count: 5,262

13 Number of tables: 3

14 Number of figures: 6

15 Abstract

16 When listening to musical rhythm, humans can perceive and move to beat-like metrical pulses.

17 Recently, it has been hypothesized that meter perception is related to brain activity responding to the

18 acoustic fluctuation of the rhythmic input, with selective enhancement of the brain response elicited

19 at meter-related frequencies. In the current study, the electroencephalography (EEG) was recorded

20 while younger $(<35)$ and older $(>60)$ adults listened to rhythmic patterns presented at two different tempi while intermittently performing a tapping task. Despite significant hearing loss compared to younger adults, older adults showed preserved brain activity to the rhythms. However, age effects were observed in the distribution of amplitude across frequencies. Specifically, in contrast with younger adults, older adults showed relatively larger amplitude at the frequency corresponding to the rate of individual events making up the rhythms as compared to lower meter-related frequencies. This difference is compatible with larger N1-P2 potentials as generally observed in older adults in response to acoustic onsets, irrespective of meter perception. These larger low-level responses to sounds have been linked to processes by which age-related hearing loss would be compensated by cortical sensory mechanisms. Importantly, this low-level effect would be associated here with relatively reduced neural activity at lower frequencies corresponding to higher-level metrical grouping of the acoustic events, as compared to younger adults.

\section{Introduction}

33 When listening to music, listeners entrain to regularities that are perceived as a musical beat, an 34 integral part of music perception (Huron, 2006). These regularities are usually organized into a meter.

35 A metrical structure consists of a pattern of nested pulse-like beats, which can be, but are not 


\section{AGING, NEURAL PROCESSING AND RHYTHM}

necessarily, prominent in the acoustic signal itself (Large, 2008). Increasing evidence suggests that meter perception may be related to selective enhancement of neural activity at the meter periodicities and their harmonics. This selective enhancement can be observed in the EEG signal recorded while listeners are presented with a rhythmic pattern inducing perception of a metrical structure (Lenc et al., 2018, 2020, 2021; Nozaradan et al., 2011, 2012, 2016). This selective enhancement has been observed not only in response to regular rhythms with high acoustic energy at the meter frequencies but also in syncopated rhythms, with no prominent acoustic cues to the meter frequencies. These observations suggest that this enhanced neural activity at the meter-related frequencies is not simply stimulus-driven or driven by low-level subcortical processes of the auditory system (Nozaradan, Keller, Rossion \& Mouraux, 2018; see also Lenc et al., 2018, 2020, 2021; Nozaradan et al., 2016).

Little is known about the neural processing of rhythmic inputs in older adults. What is known is focused on speech perception, where overall, the literature suggests that older adults respond more strongly but less precisely to temporally regular stimulation at low (speech-paced) frequencies, approximately 3-4 Hz (Anderson et al., 2012; Bidelman et al., 2014; Goossens et al., 2016; Henry et al., 2017; Herrmann et al., 2016; Presacco et al., 2016), a pattern ascribed to the inhibition theory of aging (Caspary et al., 2008; Salthouse \& Meinz, 1995). This theory ascribes an increase in overall brain activity to a decrease in GABA, an inhibitory neurotransmitter, in the aging brain (Caspary et al., 2008). This decrease in inhibitory activity can also explain the decrease in temporal encoding precision often observed in older compared to younger adults (Anderson et al., 2012; Presacco et al., 2016).

On the other hand, the few pieces of evidence about music perception in older adults suggests that it is generally preserved (Halpern et al., 1995, 1996, 1998, 2017). In some cases the performance of a musical task is preserved, but the underlying brain activity changes, suggesting that older adults may automatically compensate for declining cognitive or perceptual abilities in the musical domain (Halpern et al., 2017; Lagrois et al., 2018). This may be due to the development of compensatory mechanisms similar to those found for speech in noise perception, where older adults use contextual information to help overcome age-related changes in hearing and cognitive abilities (Birren \& Fisher, 1995; Horn, 1982; Horn \& Cattell, 1967; Madden, 1992; Pichora-Fuller et al., 1995). When rating the fit of a note in a melody, older adults rely more heavily on scale degree information, derived from knowledge of the tonal hierarchy, whereas younger adults rely more heavily on note-to-note information (Bharucha \& Krumhans1, 1983; Halpern et al., 2017). In addition to increased use of contextual and crystalized knowledge, the neural compensation theory of aging stems from the observation of patterns of over- and under-activation, reduced asymmetry and reduced connectivity of brain activity in the brains of older adults as compared to younger adults when performing a similar task at a similar level (Cabeza, 2002; Cabeza et al., 2004; Davis et al., 2011; Grady et al., 2003; Reuter-Lorenz, 2002; Reuter-Lorenz et al., 2000; Reuter-Lorenz \& Cappell, 2008). For example, a frontal shift in activity has been observed in older adults associated with compensation for declining perceptual abilities (Park \& Reuter-Lorenz, 2009).

In terms of rhythm perception, Sauvé et al. (2019) used frequency tagging to compare neural activity in older and younger adults while passively listening to a metronome. This study found that older adults, compared to younger adults, had reduced amplitude of neural activity at the frequency of the metronome and to a lesser extent also at the first three harmonics of the metronome frequency (Sauvé et al., 2019), which could not be fully accounted for by age-related changes in hearing as measured by pure-tone thresholds. In other words, older adults demonstrated a reduced response to the metronome frequency compared to younger adults, a pattern in line with literature suggesting that temporal precision degrades in the aging brain (Anderson et al., 2012; Herrmann et al., 2019). 


\section{AGING, NEURAL PROCESSING AND RHYTHM}

82

83

84

85

86

87

88

89

90

91

92

93

94

95

96

97

98

99

100

101

102

103

104

105

106

107

108

109

110

111

112

113

114

115

116

117

118

The goal of the current study was to explore differences in neural processing of rhythm between older adults and younger adults actively listening to two rhythms. One rhythm contained prominent acoustic energy at the meter-related frequencies compared to meter-unrelated frequencies (i.e. nonsyncopated rhythm). In contrast, the second rhythm was characterized by a lack of prominent acoustic energy at meter-related frequencies compared to meter-unrelated frequencies (i.e., syncopated rhythm; see Lenc et al. 2018, 2020). In the syncopated rhythm, perception of the meter thus likely relies on endogenous processes, and selective enhancement of the neural activity at meterrelated frequencies cannot be explained by acoustic confound or subcortical processing enhancing prominent acoustic features of the input (Lenc et al. 2020). To the best of our knowledge, the current study is thus the first to explore the impact of aging on neural processing of rhythm, especially when the meter is inferred but not conveyed by a strictly (i.e. metronomic) or strongly periodic (i.e. nonsyncopated) stimulus.

Based on our previous findings (Sauvé et al., 2019), together with the fact that older adults have increased exposure to musical patterns due to their age, and that older adults rely on internalized musical structure as a way to compensate for an age-related hearing impairment as compared to younger adults (Halpern et al., 2017), it is expected that older adults will show similar neural activity to younger adults in response to both rhythms despite age-related hearing loss, thus with preserved selective enhancement at the meter-related frequencies irrespective of rhythm complexity. Moreover, given known topographic neural shifts associated with aging (e.g. Park \& Reuter-Lorenz, 2009), we also examined possible differences in topographic maps between older and younger adults.

\section{Materials and Methods}

\subsection{Participants}

Twenty-nine participants (the same as in Sauvé et al., 2019) took part in this study and provided written informed consent in accordance with the Interdisciplinary Committee on Ethics in Human Research at Memorial University of Newfoundland. Participants were divided into two age groups: 15 older adults ( $>60$ yrs; 10 female) and 14 younger adults $(<25 \mathrm{yrs} ; 7$ female). All participants selfreported being healthy, right-handed and free of any cognitive deficit. All participants were nonmusicians although some had music training in childhood. Hearing abilities were assessed using standard clinical pure-tone (PT) audiometry, which revealed significant differences between the two age groups as detailed in Table 1. All participants received a small cash honorarium for their participation. Table 1 summarizes participant demographics.

Table 1. Participant Demographics

\begin{tabular}{llll}
\hline & Age & $\begin{array}{l}\text { Formal Education } \\
(\text { Years) }\end{array}$ & $\begin{array}{l}\text { Pure-tone Average (dB } \\
\text { HL)** }\end{array}$ \\
\hline $\begin{array}{l}\text { Younger } \\
\begin{array}{l}\text { Adults } \\
\text { Older Adults }\end{array}\end{array}$ & $20.3(1.84)$ & $14.6(2.23)$ & $6.2(5.07)$ \\
\hline
\end{tabular}

$* \mathrm{t}(28)=1.6, \mathrm{p}=.12$; standard deviation in brackets

** Binaural average of pure-tone threshold at 500, $1000 \& 2000 ; \mathrm{t}(28)=40.55, \mathrm{p}<.001$; standard deviation in brackets 


\section{AGING, NEURAL PROCESSING AND RHYTHM}

\subsection{Stimuli}

The selected rhythmic patterns were similar to those of previous studies (Nozaradan et al., 2016, 2017; Nozaradan, Schönwiesner, et al., 2018; see also Lenc et al., 2018) and presented into four conditions: two rhythms (non-syncopated and syncopated) at two tempi (slow: $0.416 \mathrm{~Hz}$ cycle rate, i.e. rhythmic pattern of $2400 \mathrm{~ms}$ duration; and fast: $0.833 \mathrm{~Hz}$ cycle rate, i.e. $1200 \mathrm{~ms}$ pattern duration). One of the hallmarks of aging is that older adults tend to have more difficulty processing stimuli presented at a faster rate (Salthouse \& Meinz, 1995). It is therefore possible that differences between older and younger adults are more pronounced at a higher tempo. The structure of the rhythms was based on the alternation of 12 events, consisting of sounds and silent intervals. The individual sounds consisted of $1000 \mathrm{~Hz}$ pure tones, presented at $\sim 75 \mathrm{~dB}$ SPL, with $10 \mathrm{~ms}$ rise and fall times, and were either $100 \mathrm{~ms}$ or $200 \mathrm{~ms}$ long for the fast or slow tempo, respectively. All stimuli were presented via insert earphones (Etymotic E3A). As described in Nozaradan et al. (2016) and Lenc et al. (2018), rhythms were designed to induce the perception of a meter based on a preference for grouping by 2 and 4 events per cycle (grouping by 4 events corresponding to the periodicity mostly tapped by participants when asked to tap on the rhythm; see Lenc et al., 2018). The first rhythm was non-syncopated, with regular structure congruent with the periodicities perceived as the meter, while the second rhythm was syncopated, with no prominent acoustic structure matching the perceived meter periodicities. Stimuli were generated in Reaper (V 5.16), and presented to participants using Eprime (V 3.0).
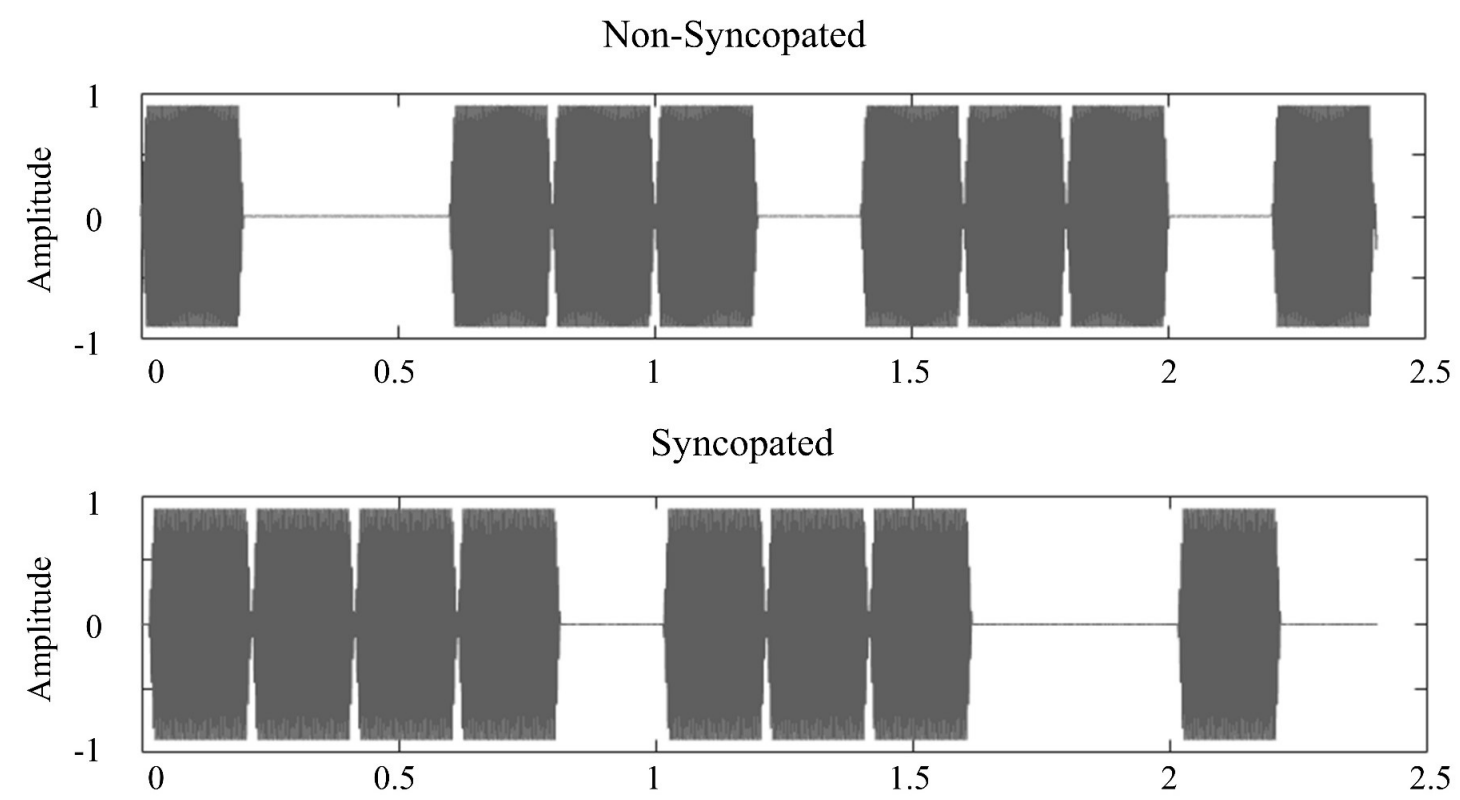

Figure 1. Audio signal representation of the non-syncopated and syncopated rhythms at slow tempo (with $200 \mathrm{~ms}$ individual sounds).

\subsection{Procedure}

140 After providing written informed consent, participants completed a short demographics

141 questionnaire, and were given the possibility to practice tapping to the 4 rhythms that would be 


\section{AGING, NEURAL PROCESSING AND RHYTHM}

142 presented during the study. Each participant was prepared for EEG recording and was seated in a

143 double-walled, electrically shielded sound-attenuating booth (Eckel). Participants were given a

144 response box (Chronos, EPrime), and could see a computer monitor. They were further instructed to

145 tap their finger in time with the perceived beat on one of the response buttons whenever the green

146 light came up on the response box, and the computer monitor said, "Tap". When the response box

147 buttons became red, and the computer monitor said "Stop Tapping", participants were instructed to

148 stop tapping, but to maintain the beat mentally. Each participant was told that they would be expected

149 to start tapping as soon as the green light came back on. Alternating between a Tapping Phase and a

150 Listening Phase was done to ensure that participants actively maintained the meter throughout the

151 task. To avoid eye movement, participants were told to either fixate on the monitor or response box

152 during the task, and to minimize switching between the two.

153 The two rhythms (non-syncopated, syncopated) were presented at the two tempi (slow, fast) in four 154 separate blocks. The order of the blocks was identical for each participant (non-syncopated rhythm, 155 slow and fast, and then syncopated rhythm, slow and fast). This fixed order was used to ensure that 156 participants could easily tap the perceived meter during the tapping phase, and were thus likely to 157 perceive the meter also when listening without tapping. Indeed, pilot testing suggested that 158 participants had increased difficulty tapping to the fast vs. slow stimuli, and to the syncopated vs. the 159 non-syncopated rhythm, even after a short practice session. In contrast, the participants seemed 160 overall more comfortable tapping when they were first presented with the non-syncopated rhythms 161 and the slow tempi. Each block started with a Tapping Phase that lasted $48 \mathrm{~s}$. After this Tapping 162 Phase, there were 10 repetitions of a 48 s Listening Phase and a 12 s Tapping Phase.

\section{$163 \quad 2.4 \quad$ EEG data processing}

164 Neuroelectric brain activity was digitized at a sampling rate of $1024 \mathrm{~Hz}$ from 134 electrodes using 165 the radial layout system, with a highpass filter set at $0.1 \mathrm{~Hz}$ using a Biosemi ActiveTwo system 166 (Biosemi Inc., Amsterdam, Netherlands). Six electrodes were placed bilaterally at mastoid, inferior 167 ocular and lateral ocular sites.

168 Data was analysed using the Letswave $6^{1}$ (Mouraux \& Iannetti, 2008) signal processing toolbox for 169 Matlab. Eye blinks and eye movements were identified for each participant using an independent 170 component analysis (ICA). Components related to eye movements were removed from the EEG signal. Next the EEG data were referenced to the average of all scalp electrodes. Each condition was divided into ten $48 \mathrm{~s}$ epochs corresponding to the Listening Phases, and then averaged into a single 48 second epoch, yielding 4 epochs (non-syncopated slow, syncopated slow, non-syncopated fast, syncopated fast) per channel and participant. EEG data recording during the tapping phase was not used for further analysis, as the purpose of the current study was not to focus on the neural activity related to overt rhythmic movement production. However, this limited tapping data can provide a behavioral index about the perceived meter using inter-tap interval (ITI) information (see SI).

To measure the amplitude at the meter-related and meter-unrelated frequencies elicited in response to the rhythms, a fast Fourier transform (FFT) was applied to the four EEG epochs for each EEG channel and participant, with a resulting spectral resolution of approximately $0.02 \mathrm{~Hz}$ (i.e. $1 / 48 \mathrm{~s}$ ). These spectra were then corrected using a noise subtraction with bin range (+/-) 3-13. This function, which subtracts from the amplitude at each frequency bin the amplitude averaged across the neighboring frequency bins from the 3rd to the 13th bin on each side (Mouraux et al., 2011;

${ }^{1}$ https://www.letswave.org/ 


\section{AGING, NEURAL PROCESSING AND RHYTHM}

184

185

186

187

188

189

190

191

192

193

194

195

196

197

198

Nozaradan et al., 2013; 2015), thus centers the amplitude spectrum around zero. Therefore, the amplitude measured at the target frequencies should tend toward zero if no significant neural activity is elicited at those specific frequencies. The amplitude of neural activity obtained from this analysis will be referred to as simply amplitude throughout this paper.

For each condition the amplitudes at targeted frequency bins were extracted from a montage of frontocentral electrodes in increasingly large concentric circles (see Figure 2). The core circle montage was selected based on signal distribution and consistent with previous work (Lenc et al., 2018; Nozaradan et al., 2012, 2016), while each subsequent outer circle includes one electrode in each direction from the core. This analysis was done to investigate any potential topographical differences between age groups. Previous work has suggested a compensation theory of aging (Reuter-Lorenz \& Cappell, 2008), which predicts larger responses or more widespread activation in older adults. Given that the magnitude of the response and the extent of the spatial distribution are difficult to separate, it is important to test both possible effects by comparing both the magnitude of the responses, and their spatial spread. By testing topographic patterns as a function of age, the possibility of age-related differences during meter perception tasks can be explored.

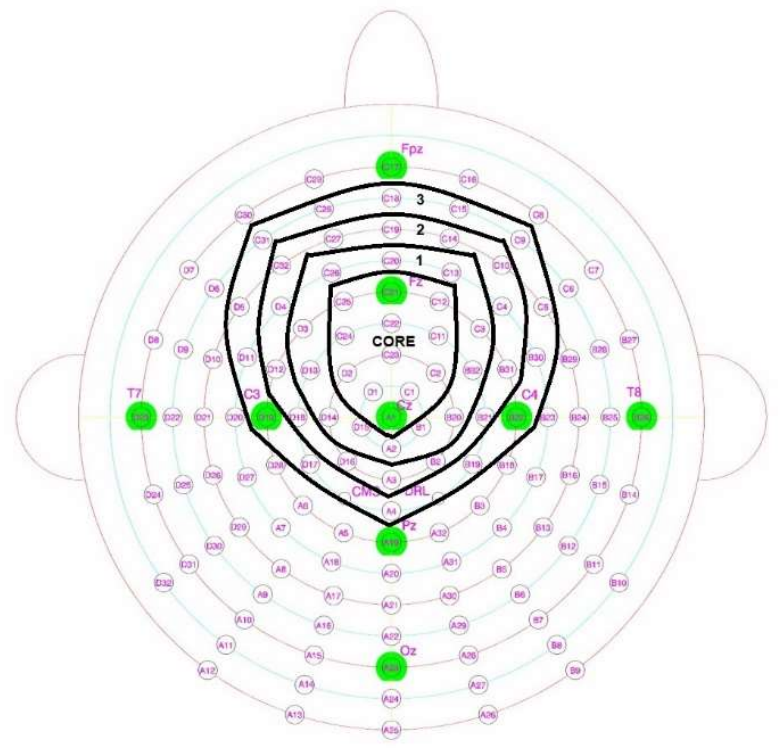

Figure 2. 128+2 radial electrode layout illustrating core and outer circle electrode montages.

As in Lenc et al. (2018), the amplitude at 12 target frequencies was extracted, corresponding to the duration of the whole pattern/cycle rate $(0.416 \mathrm{~Hz}$ or $0.833 \mathrm{~Hz}$ for the two different tempi, respectively) and its harmonics up to the period of single acoustic events $(5 \mathrm{~Hz} ; 10 \mathrm{~Hz})$. These 12 frequencies were then tagged as meter-related frequencies and meter-unrelated frequencies (Lenc et al., 2018). The meter-related frequencies were based on the periodicities of the meter assumed to be perceived for these rhythms and their harmonics, as informed by behavioral data collected in a large number of participants in previous studies and corroborated by the tapping data collected during the Tapping Phases. These meter periodicities consisted in the smallest inter-sound intervals, and grouping of these intervals by two, four, and twelve intervals (see Lenc et al., 2018 for example), thus yielding five meter-related frequencies (i.e. the first, third, sixth, ninth and twelfth frequencies 


\section{AGING, NEURAL PROCESSING AND RHYTHM}

from the 12 target frequencies, further labeled F1, F3, F6, F9 and F12). The remaining frequencies were considered meter-unrelated. Amplitudes were obtained for each frequency of interest from the closest spectral bin from each frequency.

\subsection{Statistical analysis}

Statistical analyses were conducted using mixed effects multiple linear regression modelling implemented in the R (3.3.2) lme4 (Bates, Mächler, Bolker, \& Walker, 2015) package. All analysis models were maximally fitted to reflect the experimental design, as per Barr et al. (2013), where models included random intercepts on participants and random slopes on participants by stimulus condition. All categorical variables were factors, where each level was compared to a base level. These base levels are slow for tempo, non-syncopated for rhythm, younger for age group, meterrelated for frequency type, F1 for frequency and core for electrode montage. Models were evaluated using Pearson's correlation between the model's predictions and the data along with the correlation's 95\% CIs. Statistical significance of each individual factor level for a given predictor was evaluated using 95\% CIs, where an interval not including zero indicates a significant predictor. In each analysis, follow-up independent sample two-tailed t-tests with Bonferroni correction were conducted to investigate simple effects of age.

\subsubsection{Frequency analysis}

For each participant and condition, we first averaged the amplitudes for meter-related frequencies and meter-unrelated frequencies, separately. Then, we compared the amplitude of the response at meter-related and meter-unrelated frequencies to measure selective enhancement of brain activity at meter-related frequencies across stimuli, regardless of the physical structure of the stimulus, which in the case of the syncopated rhythm, does not include prominent meter-related frequencies. To do so, a model predicting spectral amplitude of neural activity included frequency type (meter-related, meterunrelated), tempo (slow, fast), rhythm (non-syncopated, syncopated) and age group (younger, older) as fixed effects including interactions and PTAv (pure tone threshold average) score as a fixed main effect. PTAv was calculated by taking the binaural average of pure-tone threshold at 500, 1000 and $2000 \mathrm{~Hz}$ and was used to check for low-level effects of poorer hearing in older adults while channel accounts for variance between electrodes. As expected, the PTAv was larger in older adults compared to younger adults, demonstrating normative age-related changes in hearing thresholds (see Table 1).

Next, to investigate age effects on meter-related entrainment, a model predicting spectral amplitude of neural activity in response to meter-related frequencies included tempo (slow, fast), rhythm (nonsyncopated, syncopated), frequencies (F1, F3, F6, F9, F12), age group (younger, older), and PTAv score as fixed effects. In all models, interactions with PTAv were not modelled. Finally, the neural compensation hypothesis predicts more widespread activation in older adults than in younger adults (Reuter-Lorenz \& Cappell, 2008). To test this, montage (core, outer 1, outer 2, outer 3) was added to the meter-related entrainment model as a fixed effect, including interactions (except with PTAv).

\subsubsection{Tapping analysis}

The tapping task was included to ensure the participant was focusing on the metrical structure while further listening without moving. The tapping data were also used as a behavioral index confirming the assumed perceived metrical structure. As expected, participants were mostly tapping at intervals aligning with grouping by two, four or eight intervals. Because only a small number of taps were recorded between each rest period and because a proper analysis of the precision of tapping for example requires significantly higher number of taps (i.e. $>100$ in Zendel, Ross \& Fujioka, 2011), the 


\section{AGING, NEURAL PROCESSING AND RHYTHM}

254 tapping data were not used for further exploration of the tapping performance, and are thus presented

255 as supplementary materials (see Supplementary Materials 2).

\section{Results}

\section{$257 \quad 3.1 \quad$ Meter-related vs. Meter-unrelated frequencies}

258 First, we tested for selective enhancement of brain activity elicited at frequencies corresponding to

259 the meter by comparing amplitudes at meter-related frequencies vs. meter-unrelated frequencies

260 using a linear mixed effects model. Figures 3 and 4 present the brain responses along with

261 topographic maps for each meter-related frequency for the slow and fast tempi respectively. For

262 brevity, only significant predictors with $\mathrm{R}^{2}$ above .01 are included in Table 2; full tables can be found

263 in Supplementary Materials 1. Main effects of tempo (slow > fast), rhythm (non-syncopated $>$

264 syncopated) and frequency type (meter-related $>$ meter-unrelated) were significant while age group

265 and PTAv were not. Significant interactions include two-way interactions between rhythm and

266 frequency type, tempo and rhythm, age and rhythm and age and tempo, three-way interactions

267 between age, rhythm and frequency type and age, tempo, and rhythm and a four-way interaction

268 between all variables. These interactions were driven by the size of the effect of frequency type and

269 age. In the case of frequency type, the effect was smallest in the fast syncopated condition $(d=0.39)$,

270 moderate for the slow non-syncopated and slow syncopated conditions $(d=0.52$ and $d=0.43$

271 respectively), and largest for the fast non-syncopated condition $(d=0.86)$. In the case of age, Figure

2725 illustrates the size of the effects. There was no main effect of age, but there were some interactions involving age, showing that selective enhancement of meter frequencies was larger in younger adults in some conditions but not all. Figure 5 illustrates the mean amplitude of neural activity for all meterrelated and meter-unrelated frequencies and all four conditions for older and younger participants. 
Non-syncopated Rhythm

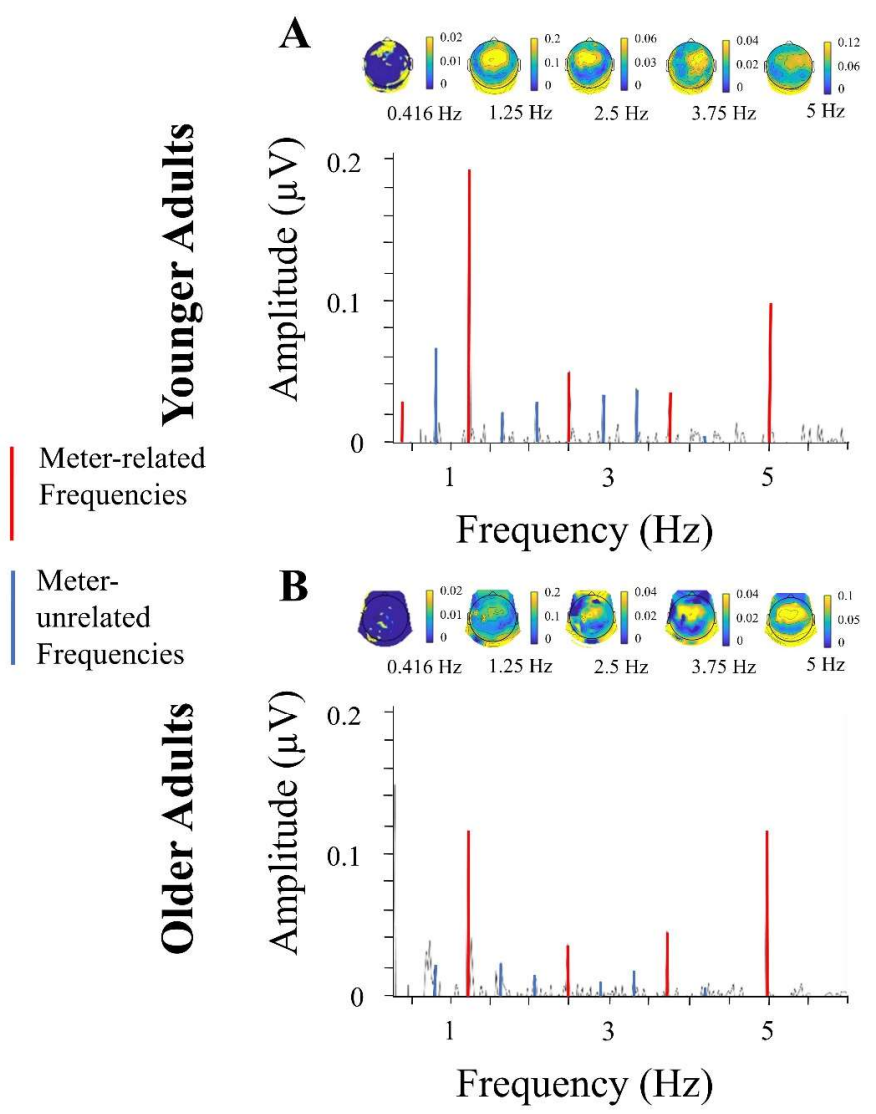

Syncopated Rhythm
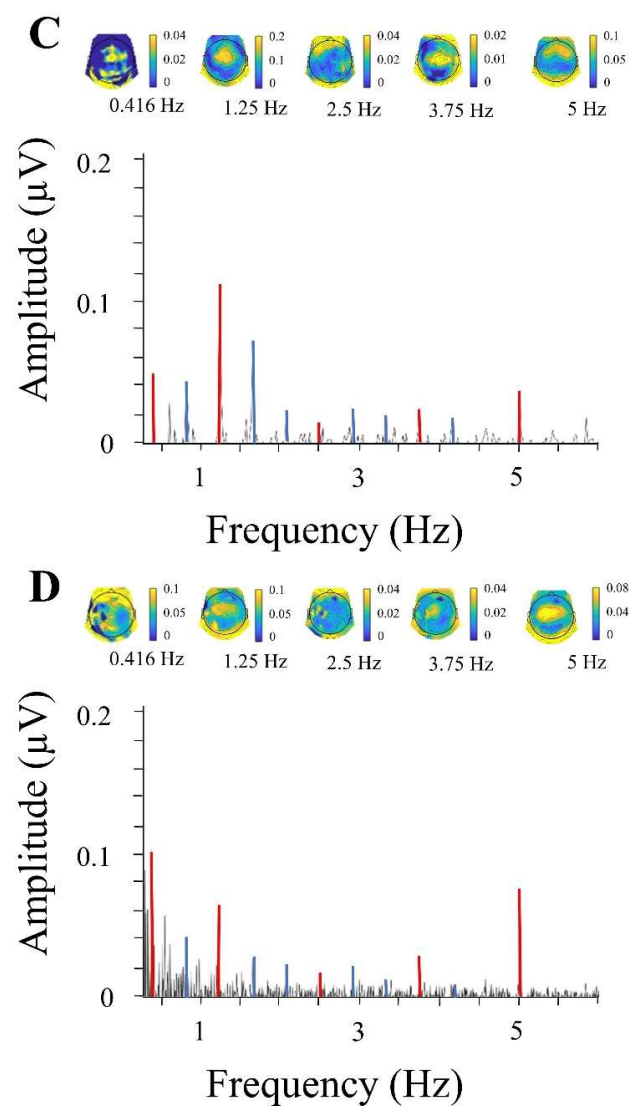

Figure 3. EEG spectra, slow tempo. Amplitude of neural activity at electrode $\mathrm{Cz}$ ranging from $0.5 \mathrm{~Hz}$ to $6 \mathrm{~Hz}$ for younger adults $(\mathrm{A}, \mathrm{C})$ and older adults $(\mathrm{B}, \mathrm{D})$ adults for non-syncopated $(\mathrm{A}, \mathrm{B})$ and syncopated $(\mathrm{C}, \mathrm{D})$ rhythms for slow tempo, along with topographic maps corresponding to each meter-related frequency. Frequency and amplitude scales are identical across conditions and groups to allow direct comparison across spectra. The scales of the topographical maps are adjusted for each condition, group and frequency for optimal visualization of topographical distribution across the EEG channels. 
Non-syncopated Rhythm

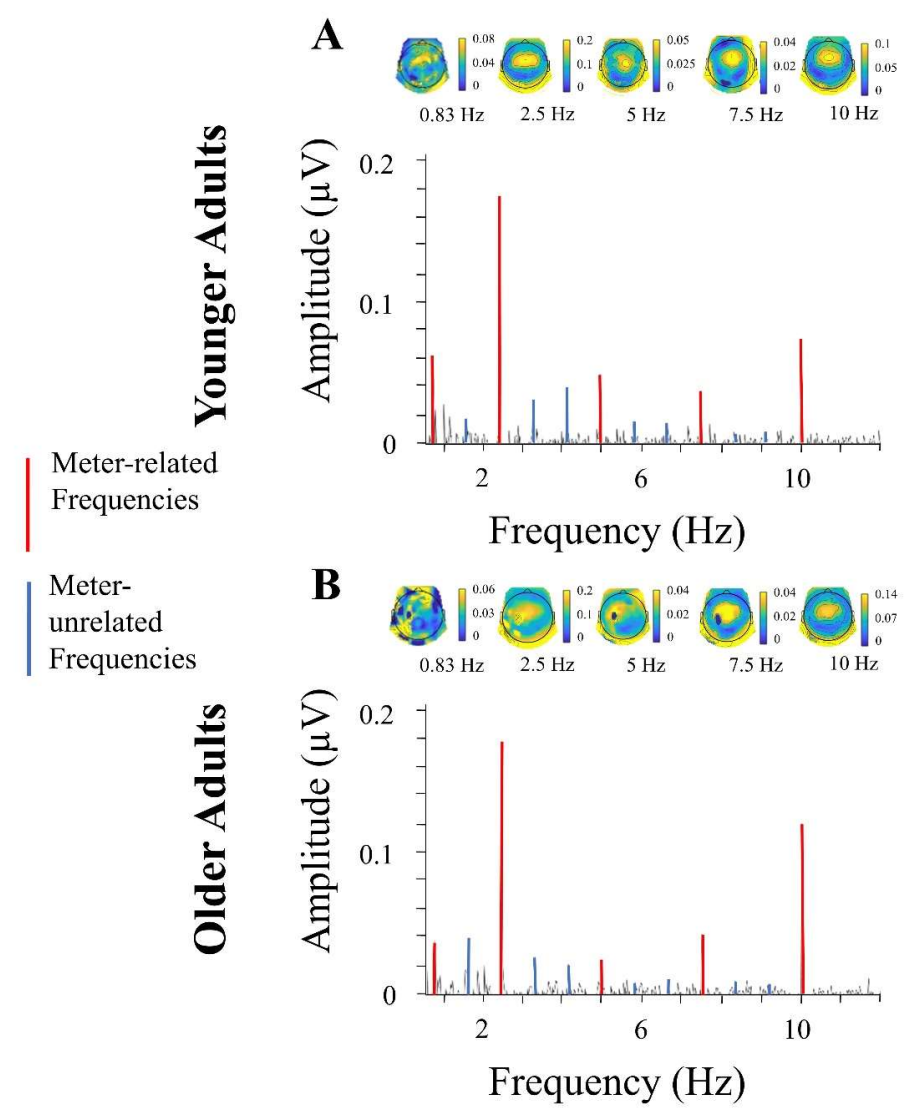

Syncopated Rhythm
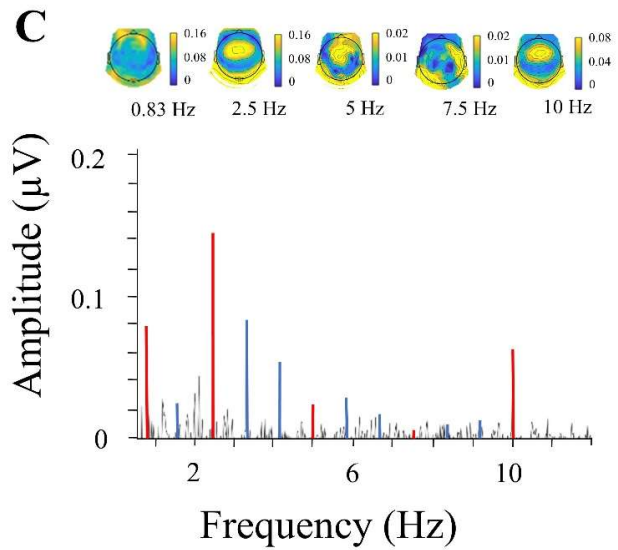

D
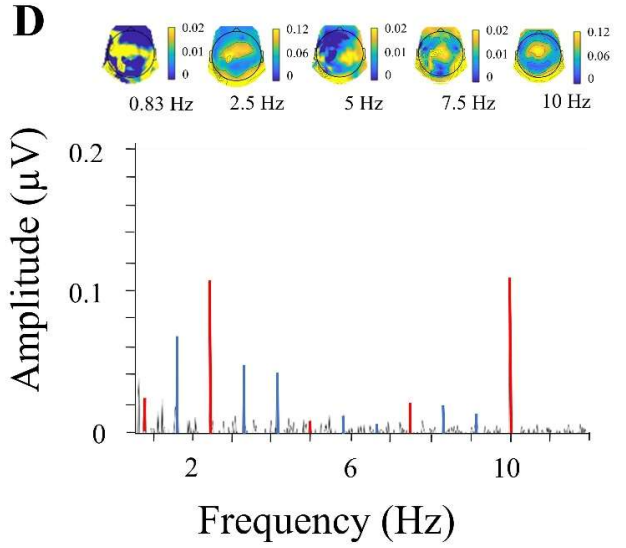

Figure 4. EEG spectra, fast tempo. Amplitude of neural activity at electrode $\mathrm{Cz}$ ranging from $0.9 \mathrm{~Hz}$ to $12 \mathrm{~Hz}$ for younger adults $(\mathrm{A}, \mathrm{C})$ and older adults $(\mathrm{B}, \mathrm{D})$ for non-syncopated $(\mathrm{A}, \mathrm{B})$ and syncopated $(\mathrm{C}, \mathrm{D})$ rhythms for fast tempo, along with topographic maps corresponding to each meter frequency.

Table 2. Summary of significant predictors with $\mathrm{R}^{2}>.01$ from the maximally fitted multiple linear regression model predicting amplitude at meter-related vs. meter-unrelated frequencies including coefficient, Wald 95\% confidence intervals and $\mathrm{R}^{2}$ for each predictor (where there are multiple

280 levels, $\mathrm{R}^{2}$ is given for the predictor as a whole). Random effects account for $<0.00$ variance and are 281 therefore not reported.

Predictor

Intercept

Coefficient

$\mathbf{2 . 5 \%}$

98.5\%

$-0.05$ $-0.04$ 

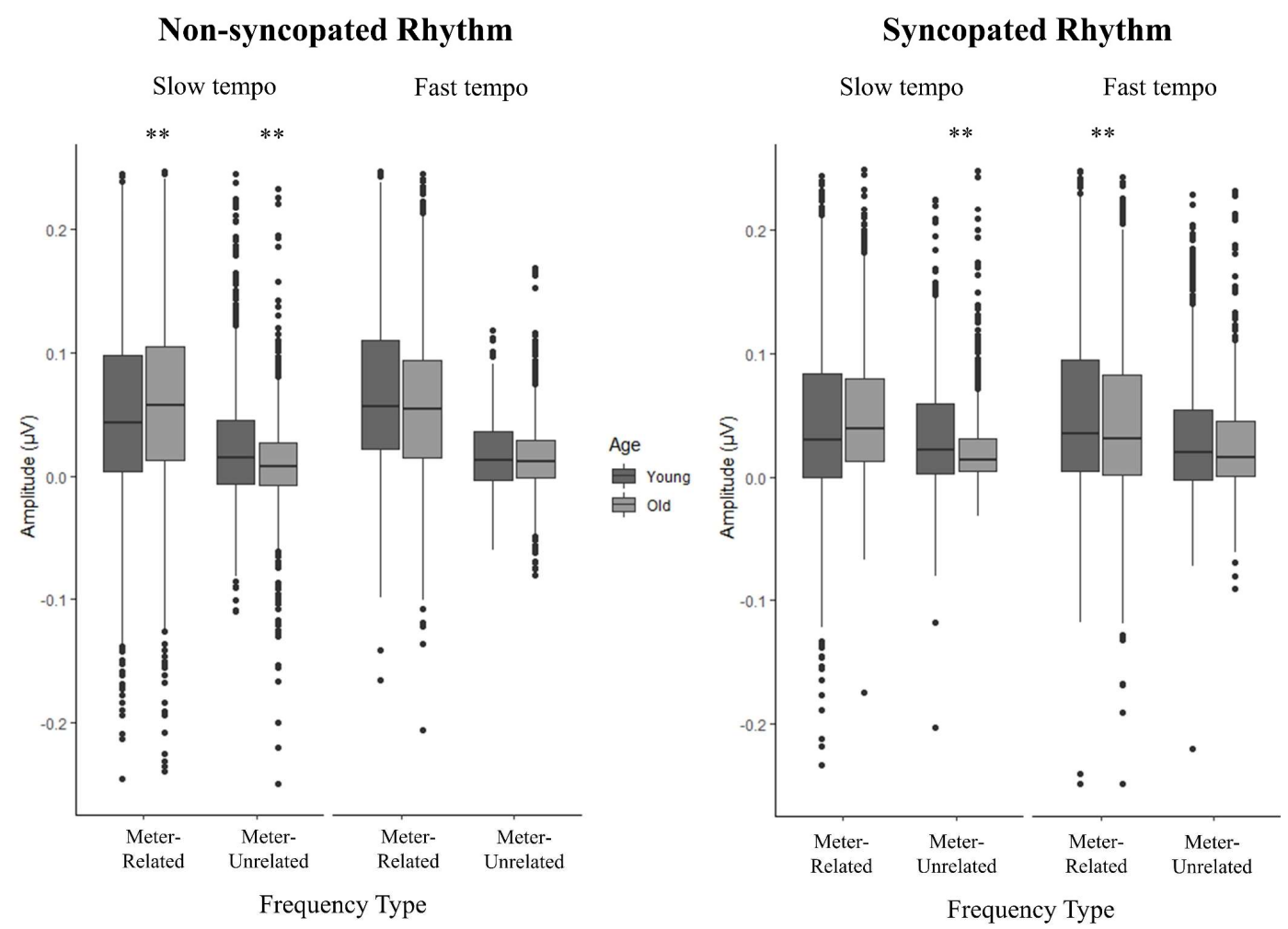

Figure 5. Amplitude of neural activity at meter-related and meter-unrelated frequencies across the four conditions and groups. Boxes represent the first quartile, median and third quartile of data, with points representing outliers; data represents amplitude values for each peak, channel and participant. $* * p<.006$ for age group comparisons.

\subsection{Amplitude across meter-related frequencies}

Next, we analyzed the amplitudes across the meter-related frequencies to determine whether the pattern of distribution of the amplitudes was affected by age (Sauvé et al., 2019). Table 3 presents the linear mixed effects model for the amplitude of neural activity elicited at meter-related frequencies for all participants across conditions. For brevity, only significant predictors with $\mathrm{R}^{2}$ above .01 were included in Table 3; full tables can be found in Supplementary Materials 1 along with corresponding summary statistics. Significant predictors included main effects of rhythm (nonsyncopated $>$ syncopated), age group (younger $>$ older), tempo (fast $>$ slow) and frequency $(F 1<F 3>F 6=F 9<$ $F 12)$ as well as multiple two-, three- and four-way interactions. To further understand the interactions of age group with tempo, rhythm and frequency, follow-up t-tests were conducted (see Supplementary Materials 1). Age effects were observed at F3 in all but one tempo and rhythm condition (fast non-syncopated), where younger adults had larger amplitudes than older adults (Figure 6). Younger adults also had significantly larger amplitudes than older adults at F6 and at F1 in all but one condition (slow syncopated), where for F6 neural activity amplitudes for both age groups are similar and for F1 older adults had larger amplitudes than younger adults. This opposite age effect, where older adults had larger amplitudes than younger adults, was observed at F12 in all 


\section{AGING, NEURAL PROCESSING AND RHYTHM}

302

303

304

305

306

307

308

309

310

311

312

313

314

315

while older adults had larger amplitudes than younger adults at F12. Figure 6 presents the mean amplitude for younger and older adults as a function of rhythm, tempo and frequency, where significant age effects are annotated with asterisks.

Finally, in order to further characterize the amplitude profiles, t-tests with Bonferroni correction were conducted between F3 and F1 and F3 and F12 amplitudes for each age group and condition (see Figure 5 and Supplementary Materials 1 for details). F3 had larger neural amplitude than F1 for both age groups in all conditions except for older adults in the slow syncopated condition, where amplitude at F1 was larger than at F3. The F3 was larger than the F12 in younger adults, while this difference was not significant in older adults, except during the fast non-syncopated condition.

Table 3. Summary of significant predictors with $\mathrm{R}^{2}>.01$ from the maximally fitted multiple linear regression model predicting neural activity amplitude at meter-related frequencies, including coefficient, Wald $95 \%$ confidence intervals and $\mathrm{R}^{2}$ for each predictor (where there are multiple levels, $\mathrm{R}^{2}$ is given for the predictor as a whole). Random effects account for $<0.00$ variance and are therefore not reported.

\begin{tabular}{lllll} 
Predictor & Coefficient & $\mathbf{2 . 5 \%}$ & $\mathbf{9 8 . 5 \%}$ & $\mathbf{R}^{\mathbf{2}}$ \\
\hline Intercept & 0.21 & 0.19 & 0.23 & .10 \\
F1 & -0.22 & -0.23 & -0.20 & \\
F6 & -0.15 & -0.16 & -0.13 & .22 \\
F9 & -0.18 & -0.19 & -0.16 & \\
F12 & -0.13 & -0.14 & -0.11 & \\
Age:F1 & 0.05 & 0.03 & 0.07 & \\
Age:F6 & 0.05 & 0.03 & 0.08 & .01 \\
Age:F9 & 0.09 & 0.07 & 0.11 & \\
Age:F12 & 0.12 & 0.10 & 0.14 & \\
Rhythm:F1 & 0.16 & 0.14 & 0.19 & \\
Rhythm:F6 & 0.06 & 0.04 & 0.08 & .03 \\
Rhythm:F9 & 0.09 & 0.07 & 0.12 & \\
Rhythm:F12 & 0.09 & 0.07 & 0.12 & \\
\hline
\end{tabular}



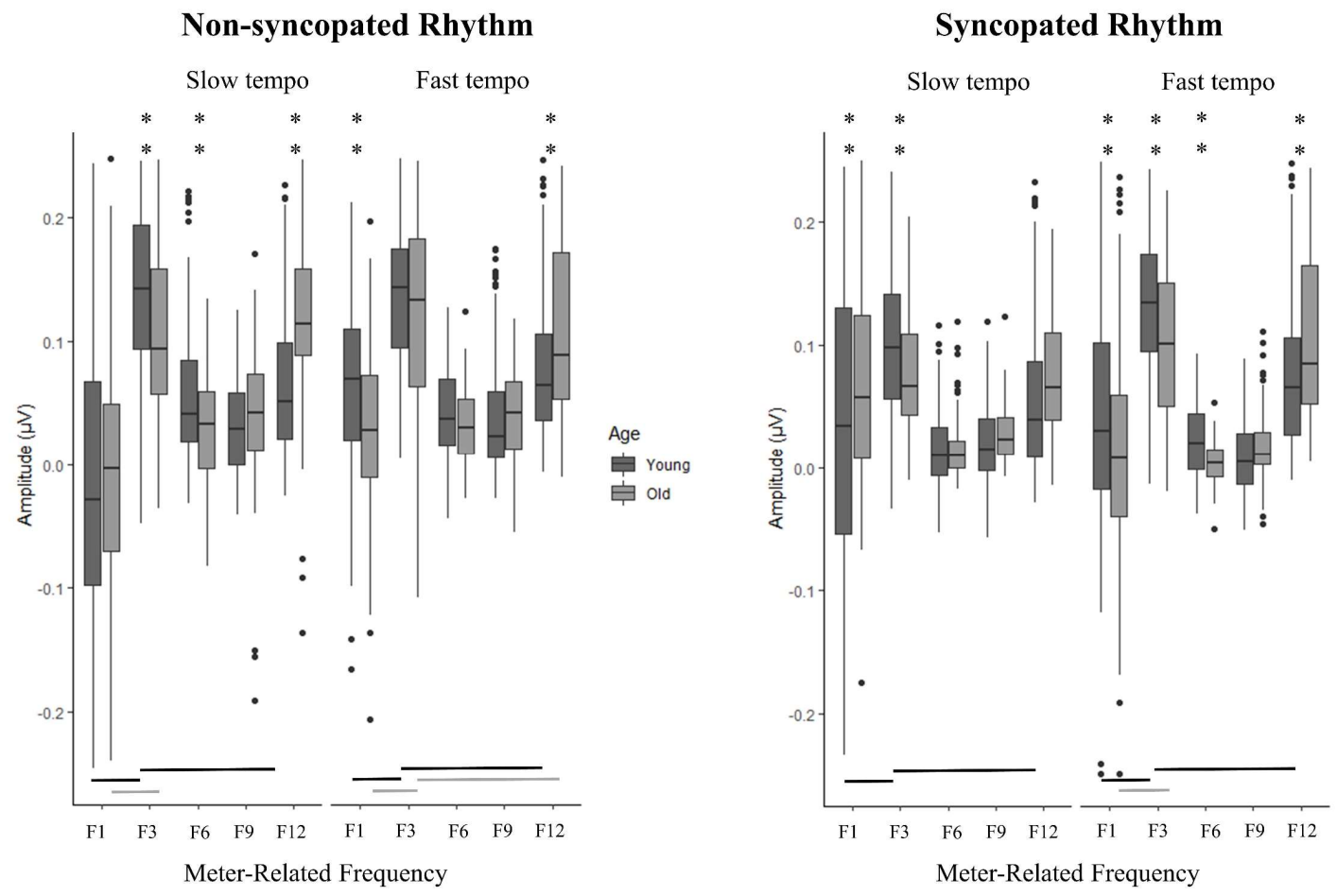

Figure 6. Amplitude of neural activity at the different meter-related frequencies across the four conditions. Boxes represent the first quartile, median and third quartile of data, with points representing outliers; data represents amplitude values for each peak, channel and participant. $* *=p<.003$, lines under the bars represent significant F1-F3 and F3-F12 frequency comparisons for each age group, $p<.006$.

\subsection{Neural compensation}

319 Finally, we investigated the distribution of the signal at meter-related frequencies to test the

320 hypothesis that older adults demonstrated more widespread neural activation than younger adults.

321 First, the main effect of montage was significant, where overall mean amplitude decreased with

322 increasing distance from the core montage. This main effect was qualified by two-way interactions with rhythm and frequency, and three-way interactions with age and frequency, and tempo and frequency. The three-way interaction involving age is driven by the difference between F3 and F12, where younger adults have larger amplitudes than older adults at F3 and vice versa for F12. In the case of rhythm, mean amplitude was always higher for non-syncopated than for syncopated rhythms but the differentiation between the two decreased as distance from the core increased $(t(6393)=$ $7.28, p<.01, t(6020)=5.11, p<.01, t(4589)=0.46, p=.0 .63$ and $t(5925)=0.32, p=.74$ for core montage to outer montage 3 respectively). Finally, in the case of frequency, the overall pattern was similar across electrode montages except for F1 where the amplitude of F1 diminished faster than the other target frequencies as distance from the core increased.

\section{Discussion}




\section{AGING, NEURAL PROCESSING AND RHYTHM}

333

334

335

336

337

338

339

340

341

342

343

344

345

346

347

348

349

350

351

352

353

354

355

356

357

358

359

360

361

362

363

364

365

366

367

368

369

370

371

372

373

374

375

376

377

378

379
In this study we examined differences between older and younger adults in neural activity to a syncopated and a non-syncopated rhythm presented at two different tempi. Overall, the amplitude of neural activity elicited at meter-related frequencies was larger compared to the activity elicited at frequencies unrelated to meter periodicities, even in the syncopated rhythm where the meter-related frequencies are not prominent acoustic features of the input. This finding is consistent with previous work (Lenc et al., 2018; 2020; Nozaradan et al., 2016, 2018). Most importantly for our experiment, this effect was similar across older and younger adults, thus suggesting that the processes by which the meter-related frequencies are selectively enhanced is preserved in aging, despite hearing loss. Moreover, the difference in pure tone audiometric thresholds between age groups did not have a significant impact on the amplitudes of neural activity. Therefore, differences in neural activity observed here between age groups are unlikely to be fully attributable to low-level hearing abilities.

Though both age groups show selective enhancement at the meter periodicities, the distribution of amplitudes across the different meter-related frequencies differs between age groups. In older adults we observe lower amplitude at F3 across stimulus conditions compared to younger adults, consistent with an overall decline in delta band frequency activity in normal aging (Polich, 1997). This age effect is in line with the findings of Sauve et al. (2019), where the same participants were listening to an isochronous rhythm at 1.25 and $2.5 \mathrm{~Hz}$, but do not directly fit with the speech neural entrainment literature which shows increased amplitude of neural activity at low (syllablepaced) frequencies of 3-4 Hz in older adults (Goossens et al., 2016; Herrmann et al., 2016, 2019). One case where younger adults showed higher neural amplitude in response to a $2.8 \mathrm{~Hz}$ frequencymodulated stimulus than older adults involved attentional control: younger adults demonstrated more activity at $2.8 \mathrm{~Hz}$ in an active task when compared to as passive task, where older adults had no difference and had activity similar to younger adults during the passive task (Henry et al., 2017). However, in Sauvé et al (2019), the task was passive so attentional control cannot explain younger adults' larger amplitudes as compared to younger adults. Furthermore, these studies only investigated neural responses at the fundamental frequency corresponding to the periodicity of the isochronous sequence, while Sauvé et al. (2019) also included harmonics of that frequency, observing a different pattern of distribution of amplitude across the fundamental frequency of stimulation and its harmonics in older adults compared to younger adults.

In the current study, younger adults demonstrate larger amplitude at F3 compared to F12 in the two rhythms and tempi, in contrast with older adults who do not show such distribution across meter-related frequencies. Sauvé et al. (2019) also observed an overall more equally distributed amplitude across the fundamental frequency and harmonics in older vs. younger adults in the EEG response to an isochronous sound at 1.25 and $2.5 \mathrm{~Hz}$. Since the difference is not modulated by rhythmic complexity, it could be explained by an aspecific change in low-level response to auditory rhythmic inputs, irrespective of meter processing. This is compatible with previous observation of larger N1-P2 evoked potentials elicited in response to auditory stimuli in older adults than younger adults (Alain \& Woods, 1999; Anderer et al., 1996; Ross et al., 2009; Zendel \& Alain, 2014). This low-level sensory effect has been linked to reduced adaptation recovery times underlying temporal processing of tone sequences (Herrmann et al., 2016). In the context of this study, it is important to note that the frequencies corresponding to individual acoustic events used to make up the inputs (i.e. frequency F12, corresponding to $200 \mathrm{~ms}$ and $100 \mathrm{~ms}$ in slow and fast tempo respectively) are congruent with the temporal course of typical N1-P2 potentials. Therefore, based on the evidence that older adults generally demonstrate larger N1-P2 amplitudes, it would be expected to find proportionally larger amplitudes at F12 compared to the slower frequency F3 in older adults compared to younger adults, regardless of rhythm complexity and tempo. As expected, this effect was found in most conditions, thus suggesting that differences in the shape of the automatic response 


\section{AGING, NEURAL PROCESSING AND RHYTHM}

380

381

382

383

384

385

386

387

388

389

390

391

392

393

394

395

396

397

398

399

400

401

402

403

404

405

406

407

408

409

410

411

412

413

414

415

416

417

418

419

420

421

422

423

424

425 to auditory stimuli between older and younger adults is likely to explain the differences observed here. This result could also be consistent with the compensation hypothesis of aging, where older adults increase activity to each single acoustic onset in order to compensate for hearing loss. The relative increase in amplitude at faster vs. slower frequencies observed here in older adults compared to younger adults is the opposite pattern to existing literature (e.g. Clinard et al., 2010; Goossens et al., 2016) and is surprising, given that perceiving and tracking beat subdivisions is more difficult than tracking a beat at fast tempi. Further research is necessary to confirm and investigate this age effect in more detail.

Our spatial analysis however does not support a compensation theory of aging. In previous literature (Halpern et al., 2017; Reuter-Lorenz \& Cappell, 2008), older adults demonstrate activity over a larger surface area in the frontal regions of the brain than younger adults. This pattern is not observed here, suggesting that older adults do not recruit larger neural areas to perform the same task as younger adults overall. Finally, the hypothesized interaction between age and rhythm, where older adults' long-term exposure to Western music may help them compensate for the lack of prominent acoustic feature at meter-related frequencies in the syncopated rhythm was not borne out in our results, suggesting that such experience did not manifest itself in this particular study.

Importantly, the design with fixed order of conditions does not appear to have had a significant effect on our results. If fatigue had been an important factor, we would expect overall neural activity to decrease from one condition to the next. This is not the case as illustrated by Figures 3 and 4, which both present the data in the same order as participants completed blocks, from left to right. However, it is impossible to parse out any potential effects of fatigue. Though this is a disadvantage of a fixed order design, it does have an advantage. Due to the endogenous nature of meter perception, one way to capture indices of the perceived meter is to ask the participants to tap periodically while listening to the rhythm. The participants of this study could successfully perform this task as indicated by the obtained mean and standard deviation of the inter-tap intervals (see SI for details), though the tapping sequences were too short to further compare tapping performance across conditions. A fixed order ensures that each participant has received the same amount of "practice" before each condition and therefore has the same opportunity to learn to mentally establish the meter in each condition, which was identified as important in pilot participants. Conversely, while a counterbalanced order design would eliminate any order or fatigue effects, meter perception in each condition may have differed due to more or less experience with the stimuli over time, depending on where the condition occurred in the experiment and was expected to be especially difficult if the fast, syncopated condition was presented first. Future work should explore a counterbalanced design to (i) ensure that the effects reported here are not related to fatigue, and (ii) exploit this potential learning effect from the order of the blocks to directly test the link between enhanced neural activity at meter frequencies and the ability to tap the perceived meter.

To summarize, this study has demonstrated subtle differences between older and younger adults on neural activity to a rhythmic stimulus. In older adults, we observed preserved selective enhancement of neural activity at meter-related frequencies despite significant hearing loss, even in the syncopated rhythms in which the meter-related frequencies were not prominent acoustic features in the input. Moreover, younger adults showed lower amplitude at the frequency corresponding to single acoustic events making up the sequences relative to the other, slower meter-related frequencies which were proportionally larger. In contrast, this difference was reduced in older adults, who showed relatively larger responses at the frequency of single acoustic events compared to activity elicited at slower frequencies. These results are compatible with previous results showing increased amplitude of N1-P2 complexes in response to single acoustic events, and indicate that this effect of 


\section{AGING, NEURAL PROCESSING AND RHYTHM}

426

427

428

429

430

431

432

433

434

435

436

437

438

439

440

441

442

443

444

445

446

447

448

449

450

451

452

453

454

455

456

457

458

459

460

461

aging can also affect responses to acoustic events presented in long rhythmic sequences. Future research is necessary to better understand the difference in response shape between younger and older adults.

\section{Conflict of Interest}

The authors declare that the research was conducted in the absence of any commercial or financial relationships that could be construed as a potential conflict of interest.

\section{Author Contributions}

SAS: Formal analysis, Writing original draft, Writing - review \& editing. ELWB: Investigation, Formal analysis. SN: Conceptualization, Methodology, Writing - review \& editing. BRZ: Conceptualization, Funding acquisition, Supervision, Resources, Writing - review \& editing. Funding

\section{$7 \quad$ Funding}

This work was supported by Dr. Zendel's Canada Research Chair in Aging and Auditory Neuroscience.

\section{References}

Alain, C., \& Woods, D. L. (1999). Age-related changes in processing auditory stimuli during visual attention: Evidence for deficits in inhibitory control and sensory memory. Psychology and Aging, 14(3), 507.

Anderer, P., Semlitsch, H. V., \& Saletu, B. (1996). Multichannel auditory event-related brain potentials: Effects of normal aging on the scalp distribution of N1, P2, N2 and P300 latencies and amplitudes. Electroencephalography and Clinical Neurophysiology, 99(5), 458-472.

Anderson, S., Parbery-Clark, A., White-Schwoch, T., \& Kraus, N. (2012). Aging Affects Neural Precision of Speech Encoding. Journal of Neuroscience, 32(41), 14156-14164. https://doi.org/10.1523/JNEUROSCI.2176-12.2012

Barr, D. J., Levy, R., Scheepers, C., \& Tily, H. J. (2013). Random effects structure for confirmatory hypothesis testing: Keep it maximal. Journal of Memory and Language, 68(3), 255-278. https://doi.org/10.1016/j.jml.2012.11.001

Bates, D., Mächler, M., Bolker, B., \& Walker, S. (2015). Fitting Linear Mixed-Effects Models Using Ime4. Journal of Statistical Software, 67(1). https://doi.org/10.18637/jss.v067.i01

Bidelman, G. M., Villafuerte, J. W., Moreno, S., \& Alain, C. (2014). Age-related changes in the subcortical-cortical encoding and categorical perception of speech. Neurobiology of Aging, 35(11), 2526-2540. https://doi.org/10.1016/j.neurobiolaging.2014.05.006

Birren, J. E., \& Fisher, L. M. (1995). Aging and speed of behavior: Possible consequences for psychological functioning. Annual Review of Psychology, 46(1), 329-353.

Cabeza, R. (2002). Hemispheric asymmetry reduction in older adults: The HAROLD model. Psychology and Aging, 17(1), 85. 


\section{AGING, NEURAL PROCESSING AND RHYTHM}

462

463

464

465

466

467

468

469

470

471

472

473

474

475

476

477

478

479

480

481

482

483

484

485

486

487

488

489

490

491

492

493

494

495

496

497

Cabeza, R., Daselaar, S. M., Dolcos, F., Prince, S. E., Budde, M., \& Nyberg, L. (2004). Taskindependent and task-specific age effects on brain activity during working memory, visual attention and episodic retrieval. Cerebral Cortex, 14(4), 364-375.

Caspary, D. M., Ling, L., Turner, J. G., \& Hughes, L. F. (2008). Inhibitory neurotransmission, plasticity and aging in the mammalian central auditory system. Journal of Experimental Biology, 211(11), 1781-1791.

Clinard, C. G., Tremblay, K. L., \& Krishnan, A. R. (2010). Aging alters the perception and physiological representation of frequency: Evidence from human FFR recordings. Hearing Research, 264(1-2), 48-55. https://doi.org/10.1016/j.heares.2009.11.010

Davis, S. W., Kragel, J. E., Madden, D. J., \& Cabeza, R. (2011). The architecture of crosshemispheric communication in the aging brain: Linking behavior to functional and structural connectivity. Cerebral Cortex, 22(1), 232-242.

Goossens, T., Vercammen, C., Wouters, J., \& Wieringen, A. van. (2016). Aging affects neural synchronization to speech-related acoustic modulations. Frontiers in Aging Neuroscience, 8, 133.

Grady, C. L., McIntosh, A. R., \& Craik, F. I. (2003). Age-related differences in the functional connectivity of the hippocampus during memory encoding. Hippocampus, 13(5), 572-586.

Halpern, A. R., Bartlett, J. C., \& Dowling, W. J. (1995). Aging and experience in the recognition of musical transpositions. Psychology and Aging, 10(3), 325.

Halpern, A. R., Bartlett, J. C., \& Dowling, W. J. (1998). Perception of mode, rhythm, and contour in unfamiliar melodies: Effects of age and experience. Music Perception: An Interdisciplinary Journal, 15(4), 335-355.

Halpern, A. R., Kwak, S., Bartlett, J. C., \& Dowling, W. J. (1996). Effects of aging and musical experience on the representation of tonal hierarchies. Psychology and Aging, 11(2), 235.

Halpern, A. R., Zioga, I., Shankleman, M., Lindsen, J., Pearce, M. T., \& Bhattarcharya, J. (2017). That note sounds wrong! Age-related effects in processing of musical expectation. Brain and Cognition, 113, 1-9.

Henry, M. J., Herrmann, B., Kunke, D., \& Obleser, J. (2017). Aging affects the balance of neural entrainment and top-down neural modulation in the listening brain. Nature Communications, 8 , 15801 .

Herrmann, B., Buckland, C., \& Johnsrude, I. S. (2019). Neural signatures of temporal regularity processing in sounds differ between younger and older adults. Neurobiology of Aging, 83, 73-85.

Herrmann, B., Henry, M. J., Johnsrude, I. S., \& Obleser, J. (2016). Altered temporal dynamics of neural adaptation in the aging human auditory cortex. Neurobiology of Aging, 45, 10-22.

Horn, J. L. (1982). The theory of fluid and crystallized intelligence in relation to concepts of cognitive psychology and aging in adulthood. In Aging and cognitive processes (pp. 237-278). Springer. 


\section{AGING, NEURAL PROCESSING AND RHYTHM}

Horn, J. L., \& Cattell, R. B. (1967). Age differences in fluid and crystallized intelligence. Acta Psychologica, 26, 107-129.

Huron, D. (2006). Sweet anticipation: Music and the psychology of expectation (2006-08683-000). The MIT Press.

Lagrois, M.-É., Peretz, I., \& Zendel, B. R. (2018). Neurophysiological and Behavioral Differences between Older and Younger Adults When Processing Violations of Tonal Structure in Music. Frontiers in Neuroscience, 12, 54.

Large, E. W. (2008). Resonating to musical rhythm: Theory and experiment. The Psychology of Time, 189-232.

Lenc, T., Keller, P. E., Varlet, M., \& Nozaradan, S. (2018). Neural tracking of the musical beat is enhanced by low-frequency sounds. Proceedings of the National Academy of Sciences, 115(32), $8221-8226$.

Lenc, T., Keller, P. E., Varlet, M., \& Nozaradan, S. (2020). Neural and behavioral evidence for frequency-selective context effects in rhythm processing in humans. Cerebral Cortex Communications.

Lenc, T., Merchant, H., Keller, P. E., Honing, H., Varlet, M., \& Nozaradan, S. (2021). Mapping between sound, brain and behaviour: Four-level framework for understanding rhythm processing in humans and non-human primates. Philosophical Transactions of the Royal Society B, 376(1835), 20200325 .

Madden, D. J. (1992). Four to ten milliseconds per year: Age-related slowing of visual word identification. Journal of Gerontology, 47(2), P59-P68.

Mouraux, A., \& Iannetti, G. D. (2008). Across-trial averaging of event-related EEG responses and beyond. Magnetic Resonance Imaging, 26(7), 1041-1054. https://doi.org/10.1016/j.mri.2008.01.011

Mouraux, A., Iannetti, G. D., Colon, E., Nozaradan, S., Legrain, V., \& Plaghki, L. (2011).

Nociceptive steady-state evoked potentials elicited by rapid periodic thermal stimulation of cutaneous nociceptors. Journal of Neuroscience, 31(16), 6079-6087.

Nozaradan, S., Keller, P. E., Rossion, B., \& Mouraux, A. (2018). EEG frequency-tagging and inputoutput comparison in rhythm perception. Brain Topography, 31(2), 153-160.

Nozaradan, S., Mouraux, A., Jonas, J., Colnat-Coulbois, S., Rossion, B., \& Maillard, L. (2017). Intracerebral evidence of rhythm transform in the human auditory cortex. Brain Structure and Function, 222(5), 2389-2404.

Nozaradan, S., Peretz, I., \& Keller, P. E. (2016). Individual differences in rhythmic cortical entrainment correlate with predictive behavior in sensorimotor synchronization. Scientific Reports, 6 , 20612.

Nozaradan, S., Peretz, I., Missal, M., \& Mouraux, A. (2011). Tagging the neuronal entrainment to beat and meter. Journal of Neuroscience, 31(28), 10234-10240. 


\section{AGING, NEURAL PROCESSING AND RHYTHM}

534 Nozaradan, S., Peretz, I., \& Mouraux, A. (2012). Selective neuronal entrainment to the beat and

535 meter embedded in a musical rhythm. Journal of Neuroscience, 32(49), 17572-17581.

536 Nozaradan, S., Schönwiesner, M., Keller, P. E., Lenc, T., \& Lehmann, A. (2018). Neural bases of rhythmic entrainment in humans: Critical transformation between cortical and lower-level representations of auditory rhythm. European Journal of Neuroscience, 47(4), 321-332.

Nozaradan, S., Zerouali, Y., Peretz, I., \& Mouraux, A. (2015). Capturing with EEG the neural entrainment and coupling underlying sensorimotor synchronization to the beat. Cerebral Cortex, $54125(3), 736-747$.

542 Park, D. C., \& Reuter-Lorenz, P. (2009). The adaptive brain: Aging and neurocognitive scaffolding. 543 Annual Review of Psychology, 60, 173-196.

544 Pichora-Fuller, M. K., Schneider, B. A., \& Daneman, M. (1995). How young and old adults listen to 545 and remember speech in noise. The Journal of the Acoustical Society of America, 97(1), 593-608.

Polich, J. (1997). On the relationship between EEG and P300: Individual differences, aging, and ultradian rhythms. International Journal of Psychophysiology, 26(1-3), 299-317.

548 Presacco, A., Simon, J. Z., \& Anderson, S. (2016). Evidence of degraded representation of speech in noise, in the aging midbrain and cortex. Journal of Neurophysiology, 116(5), 2346-2355.

550 https://doi.org/10.1152/jn.00372.2016

551

552

553

554

555

556

557

558

559

560

561

562

563

564

565

566

Reuter-Lorenz, P. A. (2002). New visions of the aging mind and brain. Trends in Cognitive Sciences, 6(9), 394-400.

Reuter-Lorenz, P. A., \& Cappell, K. A. (2008). Neurocognitive aging and the compensation hypothesis. Current Directions in Psychological Science, 17(3), 177-182.

Reuter-Lorenz, P. A., Jonides, J., Smith, E. E., Hartley, A., Miller, A., Marshuetz, C., \& Koeppe, R. A. (2000). Age differences in the frontal lateralization of verbal and spatial working memory revealed by PET. Journal of Cognitive Neuroscience, 12(1), 174-187.

Ross, B., Snyder, J. S., Aalto, M., McDonald, K. L., Dyson, B. J., Schneider, B., \& Alain, C. (2009). Neural encoding of sound duration persists in older adults. Neuroimage, 47(2), 678-687.

Salthouse, T. A., \& Meinz, E. J. (1995). Aging, inhibition, working memory, and speed. The Journals of Gerontology Series B: Psychological Sciences and Social Sciences, 50(6), P297-P306.

Sauvé, S. A., Bolt, E. L., Fleming, D., \& Zendel, B. R. (2019). The impact of aging on neurophysiological entrainment to a metronome. NeuroReport.

Zendel, B. R., \& Alain, C. (2014). Enhanced attention-dependent activity in the auditory cortex of older musicians. Neurobiology of Aging, 35(1), 55-63.

https://doi.org/10.1016/j.neurobiolaging.2013.06.022

\section{Data Availability Statement}

The datasets generated for this study are not publicly available as participants did not consent to public sharing of their data. The data is available from the corresponding author upon request. 
Supplementary Materials 1 - Summary statistics, model specification details and follow-up t-test results

Table 1. Summary statistics for meter-unrelated peaks

\begin{tabular}{|c|c|c|c|c|c|}
\hline Age & Tempo & Rhythm & Frequency & Mean Amplitude & Standard Error \\
\hline Younger & Slow & Non-syncopated & 0.83 & 0.0780057 & 0.0084729 \\
\hline Younger & Slow & Non-syncopated & 1.66 & 0.0142428 & 0.0030411 \\
\hline Younger & Slow & Non-syncopated & 2.08 & 0.0203644 & 0.0032852 \\
\hline Younger & Slow & Non-syncopated & 2.91 & 0.0375499 & 0.0039400 \\
\hline Younger & Slow & Non-syncopated & 3.33 & 0.0347361 & 0.0026435 \\
\hline Younger & Slow & Non-syncopated & 4.16 & 0.0082533 & 0.0019121 \\
\hline Younger & Slow & Non-syncopated & 4.57 & 0.0000824 & 0.0015144 \\
\hline Younger & Slow & Syncopated & 0.83 & 0.0684450 & 0.0054068 \\
\hline Younger & Slow & Syncopated & 1.66 & 0.0651119 & 0.0036049 \\
\hline Younger & Slow & Syncopated & 2.08 & 0.0422580 & 0.0032515 \\
\hline Younger & Slow & Syncopated & 2.91 & 0.0286044 & 0.0021018 \\
\hline Younger & Slow & Syncopated & 3.33 & 0.0088772 & 0.0015495 \\
\hline Younger & Slow & Syncopated & 4.16 & 0.0223526 & 0.0026422 \\
\hline Younger & Slow & Syncopated & 4.57 & 0.0026887 & 0.0014577 \\
\hline Younger & Fast & Non-syncopated & 1.66 & 0.0192275 & 0.0029082 \\
\hline Younger & Fast & Non-syncopated & 3.33 & 0.0231274 & 0.0022974 \\
\hline Younger & Fast & Non-syncopated & 4.16 & 0.0385591 & 0.0024789 \\
\hline Younger & Fast & Non-syncopated & 5.83 & 0.0149206 & 0.0023665 \\
\hline Younger & Fast & Non-syncopated & 6.66 & 0.0202689 & 0.0019773 \\
\hline Younger & Fast & Non-syncopated & 8.33 & 0.0101402 & 0.0013623 \\
\hline Younger & Fast & Non-syncopated & 9.16 & 0.0004522 & 0.0010637 \\
\hline Younger & Fast & Syncopated & 1.66 & 0.0372886 & 0.0064486 \\
\hline Younger & Fast & Syncopated & 3.33 & 0.0857562 & 0.0042886 \\
\hline Younger & Fast & Syncopated & 4.16 & 0.0579578 & 0.0039490 \\
\hline Younger & Fast & Syncopated & 5.83 & 0.0258373 & 0.0033213 \\
\hline Younger & Fast & Syncopated & 6.66 & 0.0099667 & 0.0022307 \\
\hline Younger & Fast & Syncopated & 8.33 & 0.0052247 & 0.0019539 \\
\hline Younger & Fast & Syncopated & 9.16 & 0.0143075 & 0.0013541 \\
\hline Older & Slow & Non-syncopated & 0.83 & 0.0159153 & 0.0068904 \\
\hline Older & Slow & Non-syncopated & 1.66 & 0.0231684 & 0.0033219 \\
\hline Older & Slow & Non-syncopated & 2.08 & 0.0068296 & 0.0024809 \\
\hline Older & Slow & Non-syncopated & 2.91 & 0.0058791 & 0.0021596 \\
\hline
\end{tabular}




$\begin{array}{llllll}\text { Older } & \text { Slow } & \text { Non-syncopated } & 3.33 & 0.0148497 & 0.0025553 \\ \text { Older } & \text { Slow } & \text { Non-syncopated } & 4.16 & 0.0011534 & 0.0018447 \\ \text { Older } & \text { Slow } & \text { Non-syncopated } & 4.57 & 0.0052663 & 0.0014733 \\ \text { Older } & \text { Slow } & \text { Syncopated } & 0.83 & 0.0526863 & 0.0049276 \\ \text { Older } & \text { Slow } & \text { Syncopated } & 1.66 & 0.0295822 & 0.0015906 \\ \text { Older } & \text { Slow } & \text { Syncopated } & 2.08 & 0.0279113 & 0.0017079 \\ \text { Older } & \text { Slow } & \text { Syncopated } & 2.91 & 0.0206890 & 0.0015823 \\ \text { Older } & \text { Slow } & \text { Syncopated } & 3.33 & 0.0157329 & 0.0012585 \\ \text { Older } & \text { Slow } & \text { Syncopated } & 4.16 & 0.0114314 & 0.0011923 \\ \text { Older } & \text { Slow } & \text { Syncopated } & 4.57 & 0.0082055 & 0.0006783 \\ \text { Older } & \text { Fast } & \text { Non-syncopated } & 1.66 & 0.0286830 & 0.0036746 \\ \text { Older } & \text { Fast } & \text { Non-syncopated } & 3.33 & 0.0266107 & 0.0022738 \\ \text { Older } & \text { Fast } & \text { Non-syncopated } & 4.16 & 0.0204777 & 0.0018767 \\ \text { Older } & \text { Fast } & \text { Non-syncopated } & 5.83 & 0.0086279 & 0.0016437 \\ \text { Older } & \text { Fast } & \text { Non-syncopated } & 6.66 & 0.0147253 & 0.0015365 \\ \text { Older } & \text { Fast } & \text { Non-syncopated } & 8.33 & 0.0070732 & 0.0010811 \\ \text { Older } & \text { Fast } & \text { Non-syncopated } & 9.16 & 0.0073590 & 0.0010355 \\ \text { Older } & \text { Fast } & \text { Syncopated } & 1.66 & 0.0500489 & 0.0082244 \\ \text { Older } & \text { Fast } & \text { Syncopated } & 3.33 & 0.0528557 & 0.0039821 \\ \text { Older } & \text { Fast } & \text { Syncopated } & 4.16 & 0.0538440 & 0.0033813 \\ \text { Older } & \text { Fast } & \text { Syncopated } & 5.83 & 0.0141220 & 0.0020992 \\ \text { Older } & \text { Fast } & \text { Syncopated } & 6.66 & 0.0096782 & 0.0012665 \\ \text { Older } & \text { Fast } & \text { Syncopated } & 8.33 & 0.0200754 & 0.0016987 \\ \text { Older } & \text { Fast } & \text { Syncopated } & 9.16 & 0.0096550 & 0.0016027\end{array}$

Table 2. Summary statistics for meter-related peaks

\begin{tabular}{lllrrr} 
Age & Tempo & Rhythm & Frequency & Mean Amplitude & Standard Error \\
\hline Younger & Slow & Non-syncopated & 0.41 & -0.0090419 & 0.0116278 \\
Younger & Slow & Non-syncopated & 1.25 & 0.2139752 & 0.0086961 \\
Younger & Slow & Non-syncopated & 2.50 & 0.0599340 & 0.0043373 \\
Younger & Slow & Non-syncopated & 3.75 & 0.0307553 & 0.0028445 \\
Younger & Slow & Non-syncopated & 5.00 & 0.0833212 & 0.0068019 \\
Younger & Slow & Syncopated & 0.41 & 0.0492761 & 0.0101707 \\
Younger & Slow & Syncopated & 1.25 & 0.1043801 & 0.0056635 \\
Younger & Slow & Syncopated & 2.50 & 0.0147049 & 0.0024240 \\
Younger & Slow & Syncopated & 3.75 & 0.0203156 & 0.0024042 \\
Younger & Slow & Syncopated & 5.00 & 0.0719328 & 0.0065555
\end{tabular}




\begin{tabular}{|c|c|c|c|c|c|}
\hline Younger & Fast & Non-syncopated & 0.83 & 0.0672375 & 0.0055117 \\
\hline Younger & Fast & Non-syncopated & 2.50 & 0.1869922 & 0.0083230 \\
\hline Younger & Fast & Non-syncopated & 5.00 & 0.0410084 & 0.0027795 \\
\hline Younger & Fast & Non-syncopated & 7.50 & 0.0382612 & 0.0037386 \\
\hline Younger & Fast & Non-syncopated & 10.00 & 0.0884871 & 0.0051882 \\
\hline Younger & Fast & Syncopated & 0.83 & 0.0745292 & 0.0100574 \\
\hline Younger & Fast & Syncopated & 2.50 & 0.1687050 & 0.0069872 \\
\hline Younger & Fast & Syncopated & 5.00 & 0.0232339 & 0.0023889 \\
\hline Younger & Fast & Syncopated & 7.50 & 0.0095987 & 0.0022955 \\
\hline Younger & Fast & Syncopated & 10.00 & 0.0799961 & 0.0050560 \\
\hline Older & Slow & Non-syncopated & 0.41 & -0.0366809 & 0.0137984 \\
\hline Older & Slow & Non-syncopated & 1.25 & 0.1300885 & 0.0066984 \\
\hline Older & Slow & Non-syncopated & 2.50 & 0.0342812 & 0.0036252 \\
\hline Older & Slow & Non-syncopated & 3.75 & 0.0431644 & 0.0035857 \\
\hline Older & Slow & Non-syncopated & 5.00 & 0.1233665 & 0.0048650 \\
\hline Older & Slow & Syncopated & 0.41 & 0.0886093 & 0.0074337 \\
\hline Older & Slow & Syncopated & 1.25 & 0.0747768 & 0.0033805 \\
\hline Older & Slow & Syncopated & 2.50 & 0.0145671 & 0.0015539 \\
\hline Older & Slow & Syncopated & 3.75 & 0.0269940 & 0.0016075 \\
\hline Older & Slow & Syncopated & 5.00 & 0.0754394 & 0.0035759 \\
\hline Older & Fast & Non-syncopated & 0.83 & 0.0286081 & 0.0059339 \\
\hline Older & Fast & Non-syncopated & 2.50 & 0.1709451 & 0.0117460 \\
\hline Older & Fast & Non-syncopated & 5.00 & 0.0308389 & 0.0021506 \\
\hline Older & Fast & Non-syncopated & 7.50 & 0.0417021 & 0.0025352 \\
\hline Older & Fast & Non-syncopated & 10.00 & 0.1190852 & 0.0058380 \\
\hline Older & Fast & Syncopated & 0.83 & 0.0185427 & 0.0067978 \\
\hline Older & Fast & Syncopated & 2.50 & 0.1005168 & 0.0048617 \\
\hline Older & Fast & Syncopated & 5.00 & 0.0041525 & 0.0011969 \\
\hline Older & Fast & Syncopated & 7.50 & 0.0163796 & 0.0019675 \\
\hline Older & Fast & Syncopated & 10.00 & 0.1102473 & 0.0049182 \\
\hline
\end{tabular}

Table 3. Summary of the maximally fitted multiple linear regression model predicting spectral amplitude for meter-related and meter-unrelated peak frequencies including coefficient, Wald $95 \%$ confidence intervals and $\mathbf{R}^{2}$ for each predictor (where there are multiple levels, $R^{2}$ is given for the predictor as a whole). Random effects account for $<0.00$ variance and are therefore not reported.

\begin{tabular}{lllll} 
Predictor & Coefficient & $2.5 \%$ & $98.5 \%$ & $\mathrm{R}^{2}$ \\
\hline Intercept & 0.078 & 0.067 & 0.089 & 0.067
\end{tabular}




$\begin{array}{lllll}\text { Type } & -0.048 & -0.054 & -0.042 & 0.075 \\ \text { Rhythm } & -0.024 & -0.033 & -0.014 & 0.001 \\ \text { Tempo } & 0.009 & 0.001 & 0.016 & 0.000 \\ \text { Age } & -0.014 & -0.030 & 0.003 & -0.000 \\ \text { PTA } & -0.000 & -0.001 & 0.000 & 0.000 \\ \text { Type:Rhythm } & 0.030 & 0.021 & 0.039 & 0.009 \\ \text { Type:Tempo } & -0.018 & -0.027 & -0.009 & 0.001 \\ \text { Rhythm:Tempo } & 0.010 & 0.001 & 0.020 & 0.000 \\ \text { Type:Age } & -0.000 & -0.009 & 0.008 & 0.000 \\ \text { Rhythm:Age } & 0.021 & 0.007 & 0.034 & 0.000 \\ \text { Tempo:Age } & 0.011 & 0.000 & 0.021 & 0.000 \\ \text { Type:Rhythm:Tempo } & -0.001 & -0.013 & 0.011 & 0.000 \\ \text { Type:Rhythm:Age } & -0.014 & -0.026 & -0.002 & 0.000 \\ \text { Type:Tempo:Age } & 0.005 & -0.008 & 0.017 & 0.001 \\ \text { Rhythm:Tempo:Age } & -0.036 & -0.049 & -0.023 & 0.001 \\ \text { Type:Rhythm:Tempo:Age } & 0.027 & 0.010 & 0.044 & 0.001\end{array}$

Table 4. Follow-up t-test results comparing age groups for meter-related and meterunrelated frequencies in each condition including t-statistic, p-value and Cohen's $d$ effect size.

\begin{tabular}{llllll} 
Tempo & Rhythm & Type & $\begin{array}{l}\mathrm{t}- \\
\text { statistic }\end{array}$ & $\begin{array}{l}\mathrm{p}- \\
\text { value }\end{array}$ & $\begin{array}{l}\text { Effect } \\
\text { size }\end{array}$ \\
\hline Slow & $\begin{array}{l}\text { Non- } \\
\text { syncopated }\end{array}$ & Related & 2.917 & 0.004 & 0.140 \\
Slow & $\begin{array}{l}\text { Non- } \\
\text { syncopated }\end{array}$ & Unrelated & 7.979 & 0.000 & 0.322 \\
Slow & Syncopated & Related & -1.088 & 0.277 & -0.053 \\
Slow & Syncopated & Unrelated & 6.199 & 0.000 & 0.252 \\
Fast & $\begin{array}{l}\text { Non- } \\
\text { syncopated }\end{array}$ & Related & 1.321 & 0.187 & 0.063 \\
Fast & $\begin{array}{l}\text { Non- } \\
\text { syncopated }\end{array}$ & Unrelated & 1.578 & 0.115 & 0.064 \\
Fast & $\begin{array}{l}\text { Syncopated } \\
\text { Fast }\end{array}$ & Related & 5.088 & 0.000 & 0.244 \\
& Syncopated & Unrelated & 1.655 & 0.098 & 0.067
\end{tabular}


Table 5. Summary of maximally fitted multiple linear regression model predicting spectral amplitude at meter-related frequency peaks, including coefficient, Wald $95 \%$ confidence intervals and $\mathbf{R}^{2}$ for each predictor (where there are multiple levels, $\mathbf{R}^{2}$ is given for the predictor as a whole). Random effects account for $<0.00$ variance and coefficients for all channel predictors are $<\mathbf{0 . 0 0}$, and are therefore not reported.

\begin{tabular}{|c|c|c|c|c|}
\hline Predictor & Coefficient & $2.5 \%$ & $98.5 \%$ & $\mathrm{R}^{2}$ \\
\hline (Intercept) & 0.216 & 0.193 & 0.240 & 0.105 \\
\hline Age & -0.078 & -0.110 & -0.046 & 0.000 \\
\hline Tempo & -0.027 & -0.044 & -0.010 & 0.007 \\
\hline Rhythm & -0.110 & -0.128 & -0.091 & -0.000 \\
\hline Peak0 & -0.223 & -0.239 & -0.207 & \multirow{4}{*}{0.224} \\
\hline Peak2 & -0.154 & -0.170 & -0.138 & \\
\hline Peak3 & -0.183 & -0.199 & -0.167 & \\
\hline Peak4 & -0.131 & -0.147 & -0.115 & \\
\hline PTA & -0.001 & -0.002 & 0.001 & 0.000 \\
\hline Age:Tempo & 0.068 & 0.045 & 0.091 & 0.000 \\
\hline Age:Rhythm & 0.054 & 0.028 & 0.080 & 0.000 \\
\hline Tempo:Rhythm & 0.091 & 0.069 & 0.114 & 0.000 \\
\hline Age:Peak0 & 0.056 & 0.034 & 0.078 & \multirow{4}{*}{0.017} \\
\hline Age:Peak2 & 0.058 & 0.036 & 0.080 & \\
\hline Age:Peak3 & 0.096 & 0.074 & 0.118 & \\
\hline Age:Peak4 & 0.124 & 0.102 & 0.146 & \\
\hline Tempo:Peak0 & 0.103 & 0.081 & 0.126 & \multirow{4}{*}{0.005} \\
\hline Tempo:Peak2 & 0.008 & -0.014 & 0.031 & \\
\hline Tempo:Peak3 & 0.034 & 0.012 & 0.057 & \\
\hline Tempo:Peak4 & 0.032 & 0.010 & 0.055 & \\
\hline Rhythm:Peak0 & 0.168 & 0.145 & 0.190 & \multirow{4}{*}{0.033} \\
\hline Rhythm:Peak2 & 0.064 & 0.042 & 0.087 & \\
\hline Rhythm:Peak3 & 0.099 & 0.077 & 0.122 & \\
\hline Rhythm:Peak4 & 0.098 & 0.076 & 0.121 & \\
\hline Age:Tempo:Rhythm & -0.106 & -0.138 & -0.075 & 0.002 \\
\hline Age:Tempo:Peak0 & -0.079 & -0.110 & -0.048 & \multirow{5}{*}{0.004} \\
\hline Age:Tempo:Peak2 & -0.052 & -0.084 & -0.021 & \\
\hline Age:Tempo:Peak3 & -0.077 & -0.108 & -0.045 & \\
\hline Age:Tempo:Peak4 & -0.077 & -0.109 & -0.046 & \\
\hline Age:Rhythm:Peak0 & 0.013 & -0.019 & 0.044 & \\
\hline Age:Rhythm:Peak2 & -0.029 & -0.060 & 0.003 & \multirow[t]{2}{*}{0.001} \\
\hline Age:Rhythm:Peak3 & -0.060 & -0.091 & -0.029 & \\
\hline
\end{tabular}




\begin{tabular}{lllll} 
Age:Rhythm:Peak4 & -0.091 & -0.122 & -0.059 & \\
Tempo:Rhythm:Peak0 & -0.142 & -0.174 & -0.110 & \\
Tempo:Rhythm:Peak2 & -0.064 & -0.096 & -0.032 & \multirow{2}{*}{0.014} \\
Tempo:Rhythm:Peak3 & -0.110 & -0.141 & -0.078 & \\
Tempo:Rhythm:Peak4 & -0.088 & -0.120 & -0.057 & \\
Age:Tempo:Rhythm:Peak0 & 0.022 & -0.022 & 0.066 & \\
Age:Tempo:Rhythm:Peak2 & 0.072 & 0.028 & 0.116 & \multirow{2}{*}{0.005} \\
Age:Tempo:Rhythm:Peak3 & 0.115 & 0.071 & 0.160 & \\
Age:Tempo:Rhythm:Peak4 & 0.143 & 0.098 & 0.187 &
\end{tabular}

Table 6. Follow-up t-test results for neural activity amplitudes at meter-related frequencies comparing age groups at each peak and condition including t-statistic, p-value and Cohen's d effect size.

\begin{tabular}{lllll} 
Peak & Condition & $\begin{array}{l}\text { t- } \\
\text { statistic }\end{array}$ & $\begin{array}{l}\text { p- } \\
\text { value }\end{array}$ & $\begin{array}{l}\text { Effect } \\
\text { size }\end{array}$ \\
\hline BF & Non-syncopated - & 1.532 & 0.127 & 0.163 \\
& Slow & & & \\
CR & Non-syncopated - & 7.642 & 0.000 & 0.764 \\
& Slow & & & \\
H1 & Non-syncopated - & 4.538 & 0.000 & 0.476 \\
& Slow & & & \\
H2 & Non-syncopated - & -2.711 & 0.007 & -0.286 \\
& Slow & & & \\
H3 & Non-syncopated - & -4.789 & 0.000 & -0.503 \\
& Slow & & & \\
BF & Syncopated - Slow & -3.122 & 0.002 & -0.334 \\
CR & Syncopated - Slow & 4.488 & 0.000 & 0.476 \\
H1 & Syncopated - Slow & 0.048 & 0.962 & 0.005 \\
H2 & Syncopated - Slow & -2.309 & 0.022 & -0.249 \\
H3 & Syncopated - Slow & -0.470 & 0.639 & -0.051 \\
BF & Non-syncopated - Fast & 4.770 & 0.000 & 0.495 \\
CR & Non-syncopated - Fast & 1.115 & 0.266 & 0.118 \\
H1 & Non-syncopated - Fast & 2.894 & 0.004 & 0.309 \\
H2 & Non-syncopated - Fast & -0.762 & 0.447 & -0.083 \\
H3 & Non-syncopated - Fast & -3.918 & 0.000 & -0.410 \\
BF & Syncopated - Fast & 4.612 & 0.000 & 0.486 \\
CR & Syncopated - Fast & 8.011 & 0.000 & 0.798 \\
H1 & Syncopated - Fast & 7.141 & 0.000 & 0.729 \\
H2 & Syncopated - Fast & -2.243 & 0.026 & -0.240 \\
& & & &
\end{tabular}


H3 Syncopated - Fast $\quad-4.289 \quad 0.000 \quad-0.449$

Table 7. Follow-up t-test results for meter-related peak frequencies comparing BF and CR for each age group and condition including t-statistic, p-value and Cohen's $d$ effect size.

\begin{tabular}{lllll} 
Age & Condition & $\begin{array}{l}\text { t- } \\
\text { statistic }\end{array}$ & $\begin{array}{l}\text { p- } \\
\text { value }\end{array}$ & $\begin{array}{l}\text { Effect } \\
\text { size }\end{array}$ \\
\hline Younger & $\begin{array}{l}\text { Non-syncopated - } \\
\text { Slow }\end{array}$ & -15.359 & 0.000 & -1.285 \\
Younger & Syncopated - Slow & -4.734 & 0.000 & -0.501 \\
Older & Non-syncopated - & -10.873 & 0.000 & -0.995 \\
& Slow & & & \\
Older & Syncopated - Slow & 1.694 & 0.092 & 0.178 \\
Younger & Non-syncopated - & -11.996 & 0.000 & -1.096 \\
& Fast & & & \\
Younger & Syncopated - Fast & -7.690 & 0.000 & -0.775 \\
Older & Non-syncopated - & -10.816 & 0.000 & -0.991 \\
& Fast & & & \\
Older & Syncopated - Fast & -9.809 & 0.000 & -0.919
\end{tabular}

Table 8. Follow-up t-test results for meter-related peak frequencies comparing BF and $\mathrm{H3}$ for each age group and condition including t-statistic, p-value and Cohen's $d$ effect size.

\begin{tabular}{|c|c|c|c|c|}
\hline Age & Condition & $\begin{array}{l}\mathrm{t}- \\
\text { statistic }\end{array}$ & $\begin{array}{l}\mathrm{p}- \\
\text { value }\end{array}$ & $\begin{array}{l}\text { Effect } \\
\text { size }\end{array}$ \\
\hline Younger & $\begin{array}{l}\text { Non-syncopated - } \\
\text { Slow }\end{array}$ & 11.834 & 0.000 & 1.085 \\
\hline Younger & Syncopated - Slow & 3.745 & 0.000 & 0.401 \\
\hline Older & $\begin{array}{l}\text { Non-syncopated - } \\
\text { Slow }\end{array}$ & 0.812 & 0.417 & 0.086 \\
\hline Older & Syncopated - Slow & -0.135 & 0.893 & -0.014 \\
\hline Younger & $\begin{array}{l}\text { Non-syncopated - } \\
\text { Fast }\end{array}$ & 10.044 & 0.000 & 0.962 \\
\hline Younger & Syncopated - Fast & 10.286 & 0.000 & 0.979 \\
\hline Older & $\begin{array}{l}\text { Non-syncopated - } \\
\text { Fast }\end{array}$ & 3.954 & 0.000 & 0.409 \\
\hline Older & Syncopated - Fast & -1.407 & 0.160 & -0.148 \\
\hline
\end{tabular}


Table 9. Summary of maximally fitted multiple linear regression model predicting spectral amplitude at meter-related frequency peaks over multiple electrode montages, including coefficient, Wald $95 \%$ confidence intervals and $R^{2}$ for each predictor (where there are multiple levels, $R^{2}$ is given for the predictor as a whole). Random effects and coefficients for all channel predictors account for $<0.00$ of model variation, and are therefore not reported.

\begin{tabular}{lllll} 
Predictor & Coefficient & $2.5 \%$ & $98.5 \%$ & $\mathrm{R}^{2}$ \\
\hline (Intercept) & 0.218 & 0.186 & 0.250 & 0.0280319 \\
Age & -0.077 & -0.122 & -0.032 & 0.0000035 \\
Tempo & -0.027 & -0.063 & 0.009 & 0.0018315 \\
Rhythm & -0.110 & -0.147 & -0.073 & 0.0000014 \\
Peak0 & -0.223 & -0.258 & -0.188 & \\
Peak2 & -0.154 & -0.190 & -0.119 & 0.0505123 \\
Peak3 & -0.183 & -0.219 & -0.148 & \\
Peak4 & -0.131 & -0.166 & -0.095 & \\
Ring1 & -0.020 & -0.056 & 0.016 & \\
Ring2 & -0.056 & -0.090 & -0.021 & 0.0039672 \\
Ring3 & -0.079 & -0.113 & -0.044 & \\
PTA & -0.001 & -0.002 & 0.001 & -0.0000017 \\
Age:Tempo & 0.068 & 0.018 & 0.118 & 0.0000158 \\
Age:Rhythm & 0.054 & 0.003 & 0.106 & 0.0000103 \\
Tempo:Rhythm & 0.091 & 0.041 & 0.141 & 0.0009352 \\
Age:Peak0 & 0.056 & 0.007 & 0.106 & \\
Age:Peak2 & 0.058 & 0.009 & 0.108 & 0.0020063 \\
Age:Peak3 & 0.096 & 0.047 & 0.146 & \\
Age:Peak4 & 0.124 & 0.075 & 0.173 & \\
Tempo:Peak0 & 0.103 & 0.053 & 0.153 & \\
Tempo:Peak2 & 0.008 & -0.042 & 0.058 & 0.0040778 \\
Tempo:Peak3 & 0.034 & -0.016 & 0.085 & \\
Tempo:Peak4 & 0.032 & -0.018 & 0.082 & \\
Rhythm:Peak0 & 0.168 & 0.118 & 0.218 & \\
Rhythm:Peak2 & 0.064 & 0.014 & 0.115 & 0.0107487 \\
Rhythm:Peak3 & 0.099 & 0.049 & 0.149 & \\
Rhythm:Peak4 & 0.098 & 0.048 & 0.148 & \\
Age:Ring1 & 0.000 & -0.049 & 0.050 & \\
Age:Ring2 & 0.032 & -0.016 & 0.080 & 0.0000157 \\
Age:Ring3 & 0.028 & -0.020 & 0.076 & \\
Tempo:Ring1 & -0.006 & -0.057 & 0.045 & 0.0000192
\end{tabular}




\begin{tabular}{|c|c|c|c|c|}
\hline Tempo:Ring2 & -0.008 & -0.057 & 0.041 & \multirow{5}{*}{0.0003398} \\
\hline Tempo:Ring3 & -0.005 & -0.055 & 0.044 & \\
\hline Rhythm:Ring1 & 0.009 & -0.042 & 0.060 & \\
\hline Rhythm:Ring2 & 0.034 & -0.015 & 0.084 & \\
\hline Rhythm:Ring3 & 0.046 & -0.003 & 0.095 & \\
\hline Peak0:Ring1 & 0.026 & -0.025 & 0.077 & \multirow{12}{*}{0.0013441} \\
\hline Peak2:Ring1 & 0.007 & -0.044 & 0.058 & \\
\hline Peak3:Ring1 & 0.015 & -0.036 & 0.067 & \\
\hline Peak4:Ring1 & 0.018 & -0.033 & 0.069 & \\
\hline Peak0:Ring2 & 0.048 & -0.002 & 0.097 & \\
\hline Peak2:Ring2 & 0.033 & -0.016 & 0.083 & \\
\hline Peak3:Ring2 & 0.048 & -0.001 & 0.097 & \\
\hline Peak4:Ring2 & 0.041 & -0.008 & 0.091 & \\
\hline Peak0:Ring3 & 0.049 & -0.000 & 0.098 & \\
\hline Peak2:Ring3 & 0.049 & 0.000 & 0.099 & \\
\hline Peak3:Ring3 & 0.069 & 0.020 & 0.118 & \\
\hline Peak4:Ring3 & 0.061 & 0.011 & 0.110 & \\
\hline Age:Tempo:Rhythm & -0.106 & -0.176 & -0.037 & 0.0024413 \\
\hline Age:Tempo:Peak0 & -0.079 & -0.149 & -0.009 & \multirow{4}{*}{0.0012833} \\
\hline Age:Tempo:Peak2 & -0.052 & -0.122 & 0.017 & \\
\hline Age:Tempo:Peak3 & -0.077 & -0.147 & -0.007 & \\
\hline Age:Tempo:Peak4 & -0.077 & -0.147 & -0.008 & \\
\hline Age:Rhythm:Peak0 & 0.013 & -0.057 & 0.082 & \multirow{5}{*}{0.0013572} \\
\hline Age:Rhythm:Peak2 & -0.029 & -0.099 & 0.041 & \\
\hline Age:Rhythm:Peak3 & -0.060 & -0.130 & 0.010 & \\
\hline Age:Rhythm:Peak4 & -0.091 & -0.161 & -0.021 & \\
\hline Tempo:Rhythm:Peak0 & -0.142 & -0.213 & -0.071 & \\
\hline Tempo:Rhythm:Peak2 & -0.064 & -0.135 & 0.007 & \multirow{3}{*}{0.0041286} \\
\hline Tempo:Rhythm:Peak3 & -0.110 & -0.180 & -0.039 & \\
\hline Tempo:Rhythm:Peak4 & -0.088 & -0.159 & -0.017 & \\
\hline Age:Tempo:Ring1 & 0.015 & -0.056 & 0.085 & \multirow{4}{*}{0.0000577} \\
\hline Age:Tempo:Ring2 & 0.051 & -0.016 & 0.119 & \\
\hline Age:Tempo:Ring3 & 0.030 & -0.038 & 0.098 & \\
\hline Age:Rhythm:Ring1 & 0.002 & -0.069 & 0.072 & \\
\hline Age:Rhythm:Ring2 & -0.020 & -0.088 & 0.048 & \multirow[t]{2}{*}{0.0000470} \\
\hline Age:Rhythm:Ring3 & -0.018 & -0.086 & 0.050 & \\
\hline Tempo:Rhythm:Ring1 & -0.006 & -0.078 & 0.066 & 0.0002310 \\
\hline
\end{tabular}




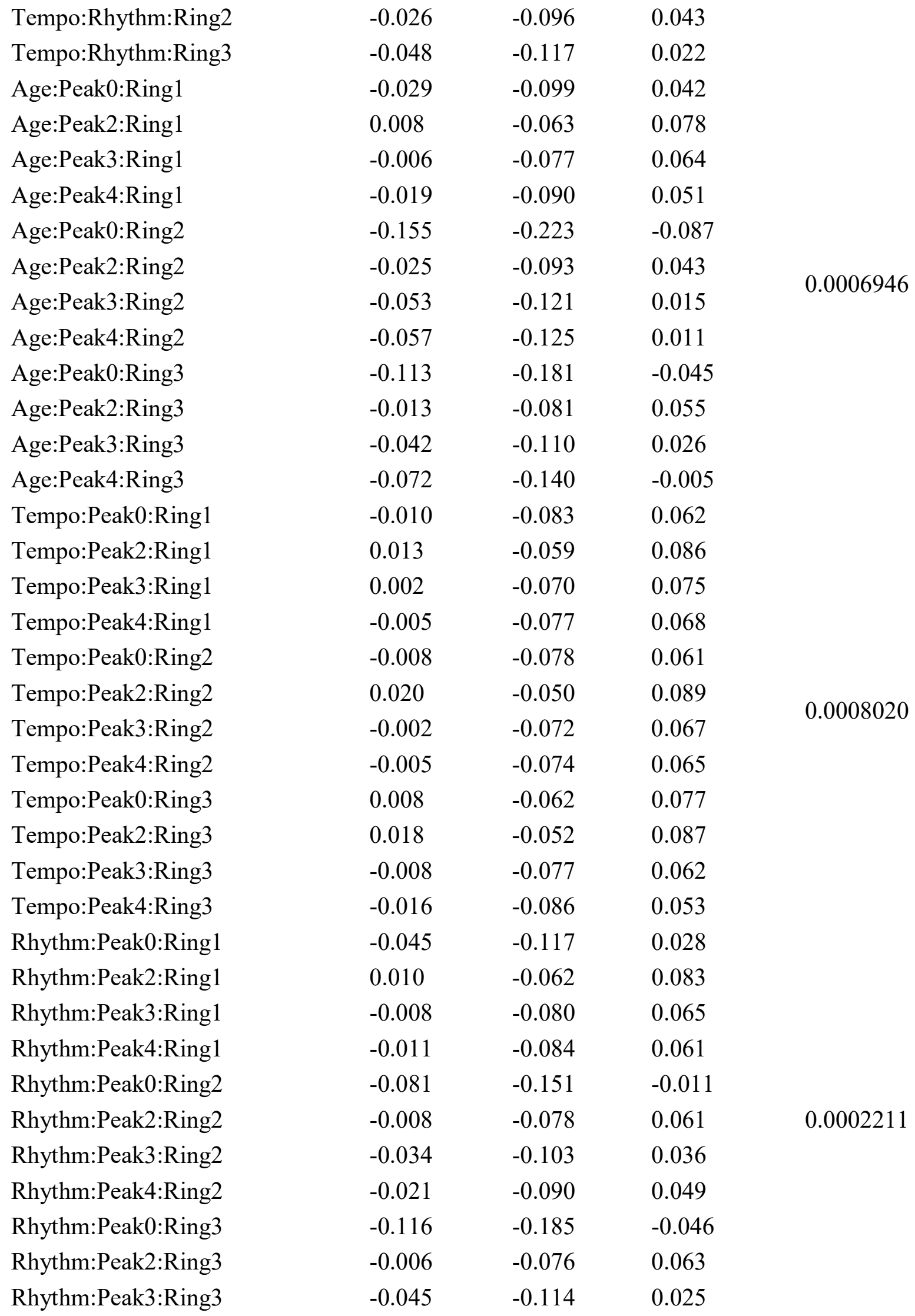




\begin{tabular}{|c|c|c|c|c|}
\hline Rhythm:Peak4:Ring3 & -0.036 & -0.106 & 0.034 & \multirow{4}{*}{0.0042622} \\
\hline Age:Tempo:Rhythm:Peak0 & 0.022 & -0.077 & 0.121 & \\
\hline Age:Tempo:Rhythm:Peak2 & 0.072 & -0.027 & 0.171 & \\
\hline Age:Tempo:Rhythm:Peak3 & 0.115 & 0.017 & 0.214 & \\
\hline Age:Tempo:Rhythm:Peak4 & 0.143 & 0.044 & 0.241 & \multirow{4}{*}{0.0001699} \\
\hline Age:Tempo:Rhythm:Ring1 & -0.002 & -0.102 & 0.098 & \\
\hline Age:Tempo:Rhythm:Ring2 & -0.041 & -0.137 & 0.055 & \\
\hline Age:Tempo:Rhythm:Ring3 & 0.012 & -0.084 & 0.108 & \\
\hline Age:Tempo:Peak0:Ring1 & 0.045 & -0.055 & 0.144 & \multirow{11}{*}{0.0004681} \\
\hline Age:Tempo:Peak2:Ring1 & -0.020 & -0.120 & 0.079 & \\
\hline Age:Tempo:Peak3:Ring1 & -0.008 & -0.107 & 0.092 & \\
\hline Age:Tempo:Peak4:Ring1 & -0.004 & -0.103 & 0.096 & \\
\hline Age:Tempo:Peak0:Ring2 & 0.094 & -0.002 & 0.190 & \\
\hline Age:Tempo:Peak2:Ring2 & -0.066 & -0.162 & 0.030 & \\
\hline Age:Tempo:Peak3:Ring2 & -0.032 & -0.128 & 0.064 & \\
\hline Age:Tempo:Peak4:Ring2 & -0.038 & -0.134 & 0.058 & \\
\hline Age:Tempo:Peak0:Ring3 & 0.087 & -0.009 & 0.183 & \\
\hline Age:Tempo:Peak2:Ring3 & -0.027 & -0.123 & 0.069 & \\
\hline Age:Tempo:Peak3:Ring3 & -0.021 & -0.117 & 0.075 & \\
\hline Age:Tempo:Peak4:Ring3 & -0.004 & -0.100 & 0.092 & \multirow{13}{*}{0.0001993} \\
\hline Age:Rhythm:Peak0:Ring1 & 0.044 & -0.056 & 0.144 & \\
\hline Age:Rhythm:Peak2:Ring1 & -0.012 & -0.112 & 0.088 & \\
\hline Age:Rhythm:Peak3:Ring1 & 0.003 & -0.096 & 0.103 & \\
\hline Age:Rhythm:Peak4:Ring1 & 0.013 & -0.087 & 0.112 & \\
\hline Age:Rhythm:Peak0:Ring2 & 0.201 & 0.105 & 0.297 & \\
\hline Age:Rhythm:Peak2:Ring2 & 0.017 & -0.079 & 0.113 & \\
\hline Age:Rhythm:Peak3:Ring2 & 0.051 & -0.045 & 0.147 & \\
\hline Age:Rhythm:Peak4:Ring2 & 0.026 & -0.070 & 0.121 & \\
\hline Age:Rhythm:Peak0:Ring3 & 0.195 & 0.099 & 0.291 & \\
\hline Age:Rhythm:Peak2:Ring3 & 0.004 & -0.091 & 0.100 & \\
\hline Age:Rhythm:Peak3:Ring3 & 0.032 & -0.064 & 0.128 & \\
\hline Age:Rhythm:Peak4:Ring3 & 0.045 & -0.050 & 0.141 & \\
\hline Tempo:Rhythm:Peak0:Ring1 & 0.057 & -0.045 & 0.160 & \multirow{5}{*}{0.000199} \\
\hline Tempo:Rhythm:Peak2:Ring1 & -0.012 & -0.114 & 0.091 & \\
\hline Tempo:Rhythm:Peak3:Ring1 & 0.010 & -0.092 & 0.112 & \\
\hline Tempo:Rhythm:Peak4:Ring1 & 0.008 & -0.095 & 0.110 & \\
\hline Tempo:Rhythm:Peak0:Ring2 & 0.101 & 0.002 & 0.199 & \\
\hline
\end{tabular}




$\begin{array}{llll}\text { Tempo:Rhythm:Peak2:Ring2 } & 0.002 & -0.096 & 0.101 \\ \text { Tempo:Rhythm:Peak3:Ring2 } & 0.043 & -0.056 & 0.141 \\ \text { Tempo:Rhythm:Peak4:Ring2 } & 0.013 & -0.086 & 0.111 \\ \text { Tempo:Rhythm:Peak0:Ring3 } & 0.163 & 0.065 & 0.262 \\ \text { Tempo:Rhythm:Peak2:Ring3 } & 0.012 & -0.086 & 0.111 \\ \text { Tempo:Rhythm:Peak3:Ring3 } & 0.068 & -0.030 & 0.167 \\ \text { Tempo:Rhythm:Peak4:Ring3 } & 0.035 & -0.063 & 0.134 \\ \text { Age:Tempo:Rhythm:Peak0:Ring1 } & -0.079 & -0.220 & 0.062 \\ \text { Age:Tempo:Rhythm:Peak2:Ring1 } & 0.015 & -0.126 & 0.156 \\ \text { Age:Tempo:Rhythm:Peak3:Ring1 } & -0.003 & -0.144 & 0.138 \\ \text { Age:Tempo:Rhythm:Peak4:Ring1 } & -0.010 & -0.151 & 0.131 \\ \text { Age:Tempo:Rhythm:Peak0:Ring2 } & -0.180 & -0.316 & -0.044 \\ \text { Age:Tempo:Rhythm:Peak2:Ring2 } & 0.056 & -0.080 & 0.191 \\ \text { Age:Tempo:Rhythm:Peak3:Ring2 } & 0.009 & -0.126 & 0.145 \\ \text { Age:Tempo:Rhythm:Peak4:Ring2 } & 0.034 & -0.102 & 0.170 \\ \text { Age:Tempo:Rhythm:Peak0:Ring3 } & -0.264 & -0.399 & -0.128 \\ \text { Age:Tempo:Rhythm:Peak2:Ring3 } & -0.004 & -0.140 & 0.131 \\ \text { Age:Tempo:Rhythm:Peak3:Ring3 } & -0.026 & -0.162 & 0.110 \\ \text { Age:Tempo:Rhythm:Peak4:Ring3 } & -0.037 & -0.173 & 0.098\end{array}$




\section{Supplementary Materials 2 - Tapping analysis}

In these supplementary materials, analysis of the tapping data is presented. Stimuli and procedure are as described in the main manuscript.

Mean inter-tap interval (ITI) was calculated for each participant and each condition and is plotted in Figure S1, where error bars represent standard deviation. Mean (standard deviation) ITIs for slow non-syncopated, fast non-syncopated, slow syncopated and fast syncopated were 781.1 (186.1), 400.34 (97.2), 791.4 (193.2) and 434.1 (135.7) respectively. A mixed effects multiple linear regression model predicting ITI with tempo, rhythm and age as fixed effects found a significant effect of tempo, but not of rhythm or age (see Table 1), nor are there any significant interactions between the predictors. More specifically, ITIs in response to fast stimuli were shorter than slow stimuli.

Together, Figure and Table 1 show that the majority of participants tapped at a metrical grouping of 4 events ( $800 \mathrm{~ms}$ for the slow tempo and $400 \mathrm{~ms}$ for the fast tempo). A few participants also tapped at a faster rate (grouping of 2 events).

Table 1. Summary of predictors from the maximally fitted multiple linear regression model predicting ITI including coefficient, Wald $95 \%$ confidence intervals and $\mathrm{R}^{2}$ for each predictor (where there are multiple levels, $\mathrm{R}^{2}$ is given for the predictor as a whole).

\begin{tabular}{lcccc}
\multicolumn{1}{c}{ Predictor } & Coefficient & $\mathbf{2 . 5 \%}$ & $\mathbf{9 8 . 5 \%}$ & $\mathbf{R}^{\mathbf{2}}$ \\
Intercept & 1464.3 & 838.6 & 2098.9 & - \\
Tempo & -530.3 & -829.9 & -230.7 & -.001 \\
Rhythm & -263.3 & -638.0 & 111.5 & .00 \\
Age & -198.4 & -594.9 & 198.1 & .00 \\
Tempo:Rhythm & 127.2 & -65.5 & 319.8 & .00 \\
Tempo:Age & 90.8 & -98.8 & 280.5 & .00 \\
Rhythm:Age & 175.0 & -60.3 & 410.2 & .00 \\
Tempo:Rhythm:Age & -74.5 & -195.0 & 46.0 & .00 \\
Random effects & & & & \\
Intercept & 21134 & & & .67 \\
Fast Nonsyncopated & 14652 & & & \\
Slow Syncopated & 27363 & & & \\
Fast Syncopated & 26364 & & & \\
Residual & 19469 & & &
\end{tabular}




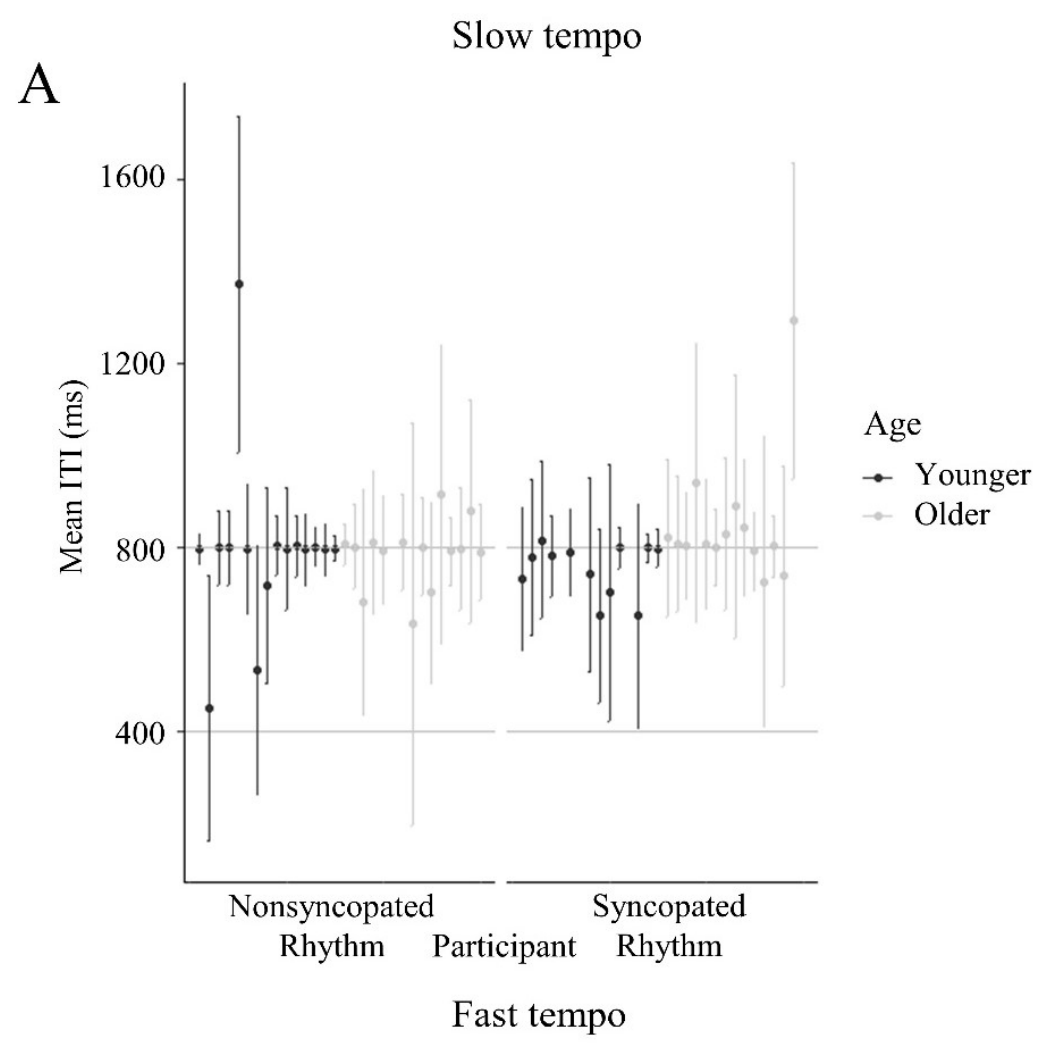

B

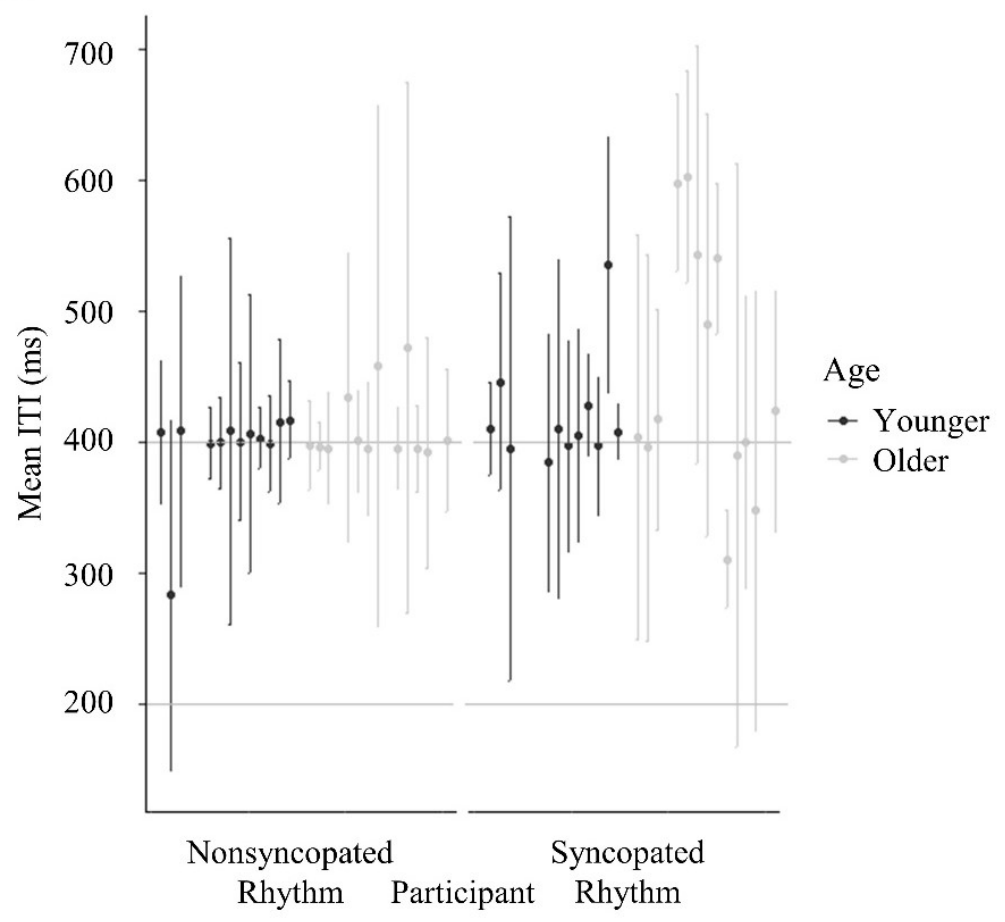

Figure S1. Mean ITI for each participant for slow (A) and fast (B) tempi and non-syncopated and syncopated rhythms, divided by age group. Error bars represent standard deviation. 